\title{
Geologically constrained morphological variability and boundary effects on embayed beaches
}

Carlos Loureiro ${ }^{a^{*}}$

Óscar Ferreira ${ }^{\text {a }}$

Andrew Cooper ${ }^{b}$

a CIMA, Centre for Marine and Environmental Research, Universidade do Algarve, Campus de Gambelas, Faro 8005-139, Portugal

${ }^{b}$ Centre for Coastal and Marine Research, School of Environmental Sciences, University of Ulster, Cromore Road, Coleraine BT52 1SA, Northern Ireland, UK

* Corresponding author

Email:carlos.loureiro@stir.ac.uk, oferreir@ualg.pt, jag.cooper@ulster.ac.uk

Published in:

Marine Geology

Volume 329-331, November 2012, Pages 1-15

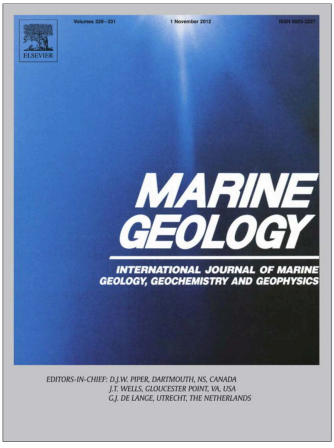

DOI: 10.1016/j.margeo.2012.09.010

URL: https://www.sciencedirect.com/science/article/pii/S0025322712002101

Marine Geology 329-331 (2012) 1-15

\begin{tabular}{cc}
\hline & Contents lists available at Sciverse ScienceDirect \\
ELSEVIER & Marine Geology \\
\hline
\end{tabular}

Geologically constrained morphological variability and boundary effects on embayed beaches

Carlos Loureiro $^{\mathrm{a}, *}$, Óscar Ferreira ${ }^{\mathrm{a}}$, J. Andrew G. Cooper ${ }^{\mathrm{b}}$

a CIMA, Centre for Marine and Environmental Research, Universidade do Algarve, Campus de Gambelas, Edificio 7, 8005-139 Faro, Portugal

${ }^{b}$ Centre for Coastal and Marine Research, School of Environmental Sciences, University of Ulster, Cromore Road, BT52 1SA, Northern Ireland, United Kingdom

A R T I C LE I N FO A B S T R A C T

This post-print author's version of the manuscript is licensed under a Creative Commons AttributionNonCommercial-NoDerivatives 4.0 International License 


\section{Research Highlights}

- Conspicuous alongshore variability was found in 6 embayment's from southern Portugal

Cross- and longshore decoupling of morphological change determined by EOF analysis

Response times increase for more constrained sites

Increased skill of normalized wave power for morphodynamic process-response relations

- Geological boundaries considerably impact sediment transport and surfzone circulation 
3

\section{Geologically constrained morphological variability and boundary effects on} embayed beaches

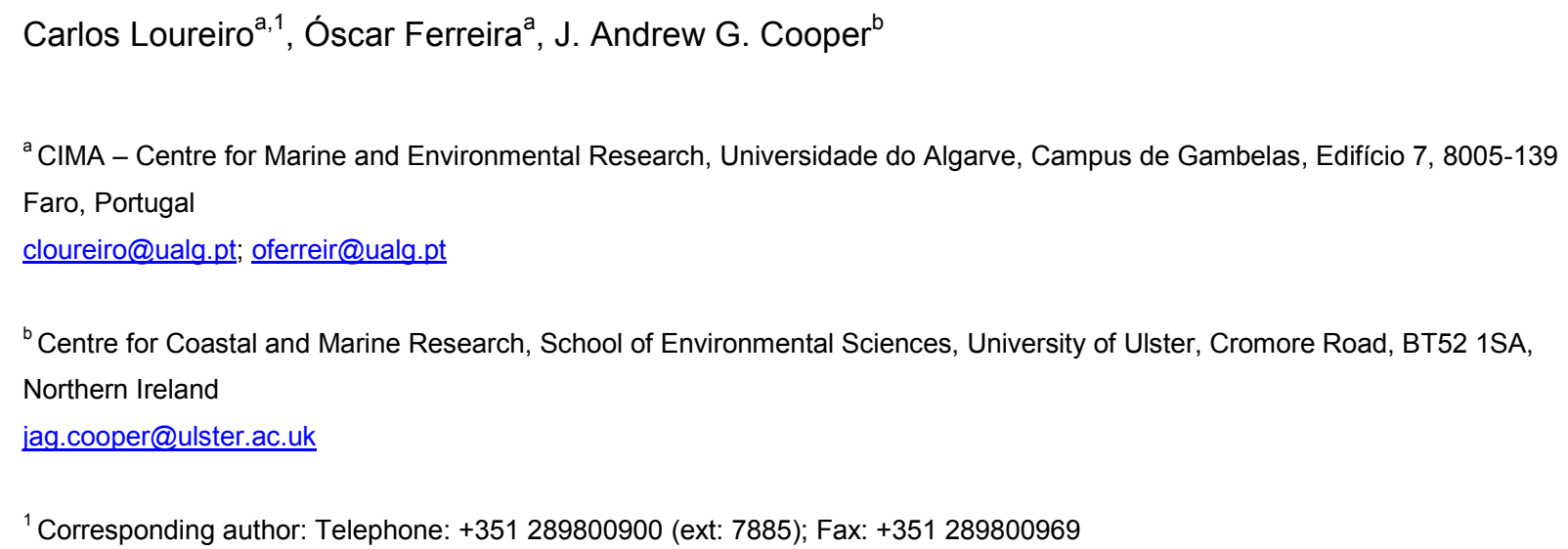

Headlands, rock outcrops and engineering structures impact beach and nearshore dynamics of coastal embayments, inducing boundary effects that constrain the lateral and vertical beach variability. This study analyses morphological change in six embayed beaches with diverse levels of exposure to wave action and various degrees of geological control in the mesotidal coast of southwestern Portugal. The aim is to identify whether geological boundaries constrain the morphological behaviour of embayed beaches and assess whether their effects can be decoupled from datasets of morphological change. Topographic data, obtained over a two-year period on each of the six embayments, were analysed using empirical orthogonal functions (EOF) to decompose temporal and spatial variability in the datasets. First and second mode eigenfunctions were explored using timevariable linear correlation analysis with several nearshore parameters that include hydrodynamic variables, sedimentary and geometric characteristics of each embayment in order to derive forcingresponse relationships.

Our results demonstrate that natural geological boundaries constrain the morphological behaviour of embayed beaches, producing conspicuous alongshore variability in all embayments. Localized responses induced by lateral and vertical boundary interference with nearshore dynamics include beach rotation, topographically-controlled rip circulation and restrained profile fluctuation. Spatial decoupling in cross- and longshore responses is accompanied by a temporal decoupling in response times, both of which are slower in more constrained embayments (from 1 day in exposed embayments to 1 week or more in the most sheltered ones). Normalized wave power was correlated at the $99 \%$ 
confidence level with the primary mode of morphological variability at most embayments, which represent $67 \%$ to $94 \%$ of the variance in the datasets. This correlation stresses the importance of combined parameterization of wave and tide forcing in process-response relations between hydrodynamics and morphological change for mesotidal coastal environments. Lateral and vertical geological boundaries exert their effects fundamentally by restraining longshore sediment transport, inducing cellular surf zone circulation and by impacting cross-shore sediment transport. It is postulated that decreasing sediment abundance and substrate depth intensify vertical boundary effects, while higher indentation and wave obliquity enhance the effects of lateral boundaries.

Keywords: coastal embayment, geological control, hard-bottom, empirical orthogonal functions, hydrodynamic forcing

\section{Introduction}

The presence of physical boundaries, in the form of headlands, rocky outcrops or even engineering structures, significantly impacts planform, sediment transport and morphodynamics of embayed beaches (Short, 1999). Suggestions that these geological constraints can be as important as dynamic forcing by waves and currents in determining contemporary beach morphology (Jackson et al., 2005) have, however, not been fully realised into the present thinking of beach morphodynamic behaviour (Jackson and Cooper, 2009). Influences of headlands, outcrops, and engineering structures in beach and surfzone dynamics are, nevertheless, frequently acknowledged regarding patterns of wave refraction and attenuation, development of cellular circulation, occurrence of sediment by-passing, and notably in the constraining of cross and longshore processes (e.g. Sanderson and Eliot, 1999; Short, 1999; Larson and Kraus, 2000; Gallop et al., 2011b; Scott et al., 2011).

While the presence of a geological framework is suggested to constrain the ability of a beach to fluctuate both laterally and vertically (Jackson and Cooper, 2009), effects of lateral boundaries, mainly due to headland control on equilibrium shoreline configuration (Silvester, 1985), have traditionally received most of the attention in the embayed beach literature (Ojeda and Guillén, 2008). Under oblique wave conditions, headland protection offers a decreasing lateral sheltering from wave action in the downdrift coastline, promoting the development of a segmented beach based on curvature, energy levels and even textural characteristics (Finkelstein, 1982; Phillips, 1985; Silvester and Hsu, 1997).This lateral boundary effect downdrift of headlands, widely explored in coastal engineering, 
decreases as wave obliquity and curvature are reduced, with the entire beach experiencing similar morphological changes (Klein et al., 2010). Irrespective of wave approach angle, as headland spacing decreases and seaward protrusion increases, other lateral boundary effects progressively modify embayed beach response (Short, 1999). In the last decade several studies have investigated the effects of lateral boundaries in natural and artificial embayed beach morphodynamics, focusing on headland restriction and modification of longshore sediment transport that imposes medium- to shortterm beach rotation (e.g. Short et al., 2000; Masselink and Pattiaratchi, 2001; Klein et al., 2002, 2010; Ranasinghe et al., 2004; Harley et al., 2008, 2011; Ojeda and Guillén, 2008; Martins et al., 2010; Ruiz de Alegria-Arzaburu and Masselink, 2010; Thomas et al. 2010, 2011; Archetti and Romagnoli, 2011). However, while knowledge of lateral constraints has been advancing, effects of vertical boundaries in the form of submerged non-erodible geological structures (e.g. Larson and Kraus, 2000; Muñoz-Perez and Medina, 2010; Gallop et al., 2011), which also impact the morphological evolution and morphodynamic responses of embayed beaches, have received only limited attention. Few studies have, so far, explored the effects of geological control in beach systems underlain by rocks, often classified as perched beaches (Gallop et al., 2011b). Recently, Jackson and Cooper (2009) presented a conceptual model detailing the general mobility of beaches with varying degrees of underlying geological control. The authors propose three types of beaches based on the relative depth of the vertical boundary (unconstrained, semi-constrained and highly constrained). However, quantitative information about the thickness of sediment veneers below which vertical geological control becomes unimportant remains undetermined (Jackson and Cooper, 2009), and field data describing vertical boundary effects is still scarce (Gallop et al., 2011a).

Various statistical methods have proved to be useful for extracting characteristic behaviour patterns from coastal morphological data (Kroon et al., 2008) and the application of empirical orthogonal functions (EOF) is considered particularly suitable for detecting and quantifying signals from different types of forcing and disturbances (Larson et al., 2003). EOF analysis has been used in beach studies for three decades, following the classical work by Winant et al. (1975), and was recently reviewed by Miller and Dean (2007a; 2007b). Those authors demonstrated the ability of EOF analysis to characterize lateral boundary effects in 20 to $45 \mathrm{~km}$-wide coastal cells, while previous studies using EOF analysis had also highlighted the role of lateral boundaries in embayed beaches (e.g. Clarke and Eliot, 1982; Short et al., 2000). It is therefore naturally appealing to consider EOF analysis as a method for quantitatively characterising the effects of both lateral and vertical boundary effects. 
Building on the body of work on the analysis of boundary effects in beach dynamics, this paper explores the range of lateral and vertical geologic constraints on the medium-term (months to years) morphologic behaviour of embayed beaches. Due to similarities between natural headlands and outcrops with engineering structures, an increased knowledge of the mechanisms of geological beach control and boundary effects is important for understanding beach behaviour in the presence of engineering structures that intend to mimic natural geological control in embayed beaches (Hsu et al., 2008). In this paper it is hypothesized that lateral and vertical geological boundaries constrain the morphological behaviour of embayed beaches and that their effects can be decoupled from datasets of embayed beach morphological change. To test this, four specific objectives are outlined:

(i) Decompose the spatial and temporal variability of embayed beach morphology at diverse sites;

(ii) Evaluate the forcing mechanisms driving the observed morphological change;

(iii) Analyse the role of vertical and lateral geological constraints on the morphological response;

(iv) Characterize boundary effects on the morphological behaviour of embayed beaches.

To address the questions and objectives raised, this paper explores EOF analysis, which, although widely used to determine shoreline and beach profile evolution, has been scarcely applied to analyse the evolution of coastal areas controlled by headlands, rocky outcrops or underlying bedrock. Datasets of morphological change from six embayed beaches from southwestern Portugal are used. The beaches are clustered into two groups of three closely located embayments, with beaches within each group exposed to identical offshore forcing. However, due to geological constraints, each beach experiences different morphological changes. The quantitative analysis based on EOF decomposition is complemented by time-variable correlation analysis with several forcing parameters combining hydrodynamic variables, sedimentary and geometric characteristics of each embayment.

\section{Field site description}

The southwestern coast of Portugal is an indented rocky coastline with marked geodynamic contrasts between the western and southern sections. Despite both being bedrock-framed, with a prevalence of embayed beaches in coastal re-entrants fronting the cliffs or associated with small streams, both geological and environmental characteristics differ significantly between these two sections. Carved in 
Carboniferous shale and greywacke, the high-energy western coastline is directly exposed to the

132 North Atlantic swell, with several intermediate to dissipative embayed beaches experiencing energetic conditions throughout the year. Mean offshore significant wave heights $\left(H_{0}\right)$ between 1.5 and $2 \mathrm{~m}$, and peak wave periods $\left(T_{\mathrm{p}}\right)$ between 9 and $13 \mathrm{~s}$ for summer and winter periods, respectively, induce a marked oceanographic seasonality (Costa and Esteves, 2010). Waves reach this coastline predominantly from north-westerly to westerly directions (Fig 1); yet nearly complete refraction of swell waves renders most of these embayed beaches swash aligned. Jurassic to Miocene calcareous cliffs constitute the majority of the rocky section of the southern coastline, which is relatively sheltered from direct exposure to the North Atlantic swell. Offshore wave conditions are moderate, with mean $H_{0}$ around $0.9 \mathrm{~m}$ and mean $T_{\mathrm{p}}$ of $8 \mathrm{~s}$ (Costa et al., 2001). Slight variations occur between summer and winter conditions, but not as markedly as on the west coast. Dominant waves reach this coastline from a W-SW direction (Fig. 1), yet shorter period SE waves generated within the Gulf of Cadiz account for roughly a quarter of occurrences (Costa et al., 2001). This oceanographic setting imposes a markedly bimodal wave climate on the sediment-starved, intermediate to reflective south coast embayed beaches. Tidal conditions are identical and nearly synchronous for both sections of the coastline. Tidal regime is classified as semidiurnal and mesotidal, with maximum spring tidal range around $3.5 \mathrm{~m}$. Six embayed beaches were selected as study sites, three in each section of the coastline (Fig. 1). West coast beaches, Amoreira, Mt. Clérigo and Arrifana, are all composed of well-sorted, medium sand, and being exposed to a high-energy wave climate these beaches are modally dissipative or intermediate skewed to dissipative. Amoreira beach is roughly $500 \mathrm{~m}$-long, but is wide and backed by an extensive dune field. This embayment contains a bay-barrier estuary, with a small tidal stream that runs through a shallow channel adjacent to the southern headland. The beach has a persistent low tide terrace, occasionally crossed by the tidal stream, which creates a ridge and runnel-like morphology. Similarly to Amoreira, the Mt. Clérigo embayment faces directly the dominant NW waves. This beach is wide and backed by partly vegetated dunes in the south and central sections, while the northern part is narrow and backed by 50 m-high cliffs. The intertidal area is wide, with rocks outcropping in the southern section of the embayment. Arrifana is a swash-aligned beach, completely enclosed by up to 100 m-high cliffs, and partially protected from dominant NW waves by a prominent northern headland. A lag deposit, composed of coarse gravel and boulders, separates the narrow subaerial beach from the cliffs. thin layers of medium to coarse sand, which generally overlie lag deposits of cobbles, boulders and/or 
shore platforms. These sediment-starved beaches are modally intermediate skewed to reflective. Salema beach is relatively unconstrained by protruding headlands, which allows it to range from 600 to $1100 \mathrm{~m}$ in length. Being openly exposed to SSE, this beach receives waves from the dominant SW swell as well as SE sea, which generally impinge on the beach with significant angles. Boca do Rio is a short, narrow beach that corresponds to the terminal part of a small infilled estuary, with a temporary stream that crosses the eastern section of the beach following rainfall events. It is also roughly exposed to SSE, and the reduced seaward protrusion of the bordering headlands also enables waves from both dominant directions to reach the shoreline. Cabanas Velhas is also narrow, and backed by 10 to 50 m-high cliffs. It is exposed directly to the dominant SW waves, being partially protected from SE waves by a protruding eastern headland.

\section{Data and methods}

\subsection{Topographic data}

Topographic surveys along cross-shore beach profiles were performed bimonthly on the study sites between September 2007 and September 2009, and complemented by event-driven surveys immediately after storm events and two to three weeks later to monitor beach recovery. Three profiles, with variable alongshore spacing (Fig.1; Table 1), were measured in each embayment using RTKGNSS (Real Time Kinematic Global Navigation Satellite System). Surveys were undertaken at low tide and extended from the frontal dune or cliff base to the mean low water spring level (MLWS), $1.4 \mathrm{~m}$ below mean sea level (MSL), or further seaward.

The selection of proxies to represent the overall beach response is non-trivial. Recent EOF analyses of alongshore beach variability have used datum-based shoreline positions, mainly extracted from time-exposure video images or profile surveys (e.g. Miller and Dean, 2007a; Fairley et al., 2009; Ruiz de Alegría-Arzaburu et al., 2010). These are, however, generally restricted to the upper portion of the cross-shore beach profile. Alternatively, EOF analyses of beach variability have also been performed using a sediment budget approach, using either digital elevation models (e.g. Larson et al., 1999; Haxel and Holman, 2004; Gómez-Pujol et al., 2011), or linear volume along cross-shore beach profiles (e.g. Clarke and Eliot, 1982, 1988). The latter proxy was selected in the present study. Profile volume was computed by trapezoidal integration with the upper limit defined by the profile surface and the MLWS level as lower limit. The MLWS level was chosen because it indicates a vertical morphodynamic separation of the beach profile for exposed beaches in southern Portugal, based on 
results presented by Almeida et al. (2011), due to the existence of a nodal point at this level that separates the cross-shore sectors dominated by berm and subtidal terrace changes.

\subsection{Empirical orthogonal function analysis}

EOF analysis is here applied to decompose the spatial and temporal variability within each dataset. Application of this multivariate statistical technique, often referred as Principal Component Analysis, to coastal geomorphology datasets has been widely described (e.g. Winant et al., 1975; Vincent et al., 1976; Aubrey, 1979; Wijnberg and Terwindt, 1995; Muñoz-Pérez et al., 2001; Dean and Dalrymple, 2002; Larson et al., 2003; Miller and Dean, 2007a). In brief, a data matrix $y(s, t)$ can be represented by a series of linear combinations of spatial and temporal functions, denoted by:

$$
y(s, t)=\sum_{\mathrm{k}=1}^{\mathrm{n}} n_{\mathrm{k}} e_{\mathrm{k}}(s) c_{\mathrm{k}}(t)
$$

where $e_{k}(\mathrm{~s})$ are the $k^{\text {th }}$ spatial eigenfunctions, $c_{k}(\mathrm{t})$ are the $k^{\text {th }}$ temporal eigenfunctions, or temporal coefficients, and $n_{k}$ the normalizing factor. The new sets of variables, $e_{k}(\mathrm{~s})$ and $c_{k}(\mathrm{t})$, are orthogonal and therefore, uncorrelated, and ordered in terms of their ability to explain the variance in the original dataset. EOF application allows the dimensionality of a dataset to be reduced (Larson et al., 2003), as generally it is necessary to retain only the first few eigenfunctions, which will account for most of the variance, providing a compact representation of the original data (Miller and Dean, 2007a).

The way the data matrix is specified for EOF analysis is central to the outcome of the calculations (Clarke and Eliot, 1988). The most important distinction involves the scaling of the variables, which were here de-meaned prior to the calculations. Such choice of scale determines that the matrix used to perform the EOF analysis is a covariance matrix. This is the most common option for EOF applications to coastal morphologic data (Larson, et al., 2003), as detailed in recent studies (e.g., Kroon et al., 2008; Fairley et al., 2009; Hansen and Barnard, 2010; Gómez-Pujol et al., 2011). The EOF modes, or eigenfunctions, obtained are thus considered in terms of changes in beach response in regard to the mean $\left(\Delta \mathrm{V}_{\mathrm{b}}{ }^{\text {mean }}(t)\right.$ given by $\mathrm{V}_{\mathrm{b}}\left(t_{i}\right)-\mathrm{V}_{\mathrm{b}}$ mean , where $\mathrm{V}_{\mathrm{b}}$ is the volume for each survey date $t_{i}$ and $\mathrm{V}_{\mathrm{b}}$ mean is the time averaged volume), which otherwise would tend to dominate the signal (Larson et al., 2003). The first EOF modes are often given physical interpretations based on resemblance of the spatial eigenfunctions with morphological features (e.g. Winant et al., 1975, 
227

228

229

230

231

232

233

234

235

236

237

238

239

240

241

242

243

244

245

246

247

248

249

250

251

252

253

254

255

256

257

Aubrey, 1979), or correlation of temporal eigenfunctions with forcing parameters (e.g. Miller and Dean, 2007b; Fairley et al., 2009).

\subsection{Comparison with forcing parameters}

Establishing relationships between different variables can provide insights into the behaviour of a beach and how it responds to forcing (Larson et al., 2003). Accordingly, a set of commonly used hydrodynamic and morphodynamic parameters were selected to characterize the forcing and relate it to the temporal eigenfunctions. The variables considered here combine wave, tide, sediment characteristics and embayment geometry, and details of their collection, transformation and application are described below.

\subsubsection{Offshore waves and tides}

Wave data have been collected by Instituto Hidrográfico $(\mathrm{IH})$ for Portuguese western and southern offshore coastal waters using Datawell directional wave buoys near Sines and Faro (Fig. 1), located both roughly $7 \mathrm{~km}$ from shore in approximately $100 \mathrm{~m}$ water depths. The buoys provide measurements of offshore significant wave height $\left(H_{0}\right)$, peak spectral period $\left(T_{\mathrm{p}}\right)$ and peak wave direction $\left(\theta_{0}\right)$. Gaps in the measured wave record, accounting for roughly $15 \%$ at Sines and $5 \%$ at Faro buoy for the duration of the study, where filled using modelled wave data from WANA deepwater network (Lahoz and Albiach, 2005), provided by Puertos del Estado for grid points near the wave buoys (Fig. 1). Linear correlation analysis indicated a statistically significant correlation between observed and modelled wave heights ( $R \geq 0.82$ for $p<0.01$; RMSE $\leq 0.4 \mathrm{~m})$.

Tide level observations and predictions for the west coast beaches were obtained from the IH tide gauge in Sines (Fig. 1). The amount of missing records in the dataset was reduced, around $2 \%$, and these were filled using the predicted tide levels at Sines. Equipment malfunction in Lagos tide gauge (Fig. 1) truncated the observed tide levels, rendering it useless, and predicted tide levels at Lagos were used for the south coast beaches.

\subsubsection{Forcing parameters}

Numerous dimensional and non-dimensional hydrodynamic and morphodynamic parameters are often used for characterizing the forcing driving beach changes. Ten parameters are considered here, namely breaker height $\left(H_{\mathrm{b}}\right)$, breaker angle $\left(\theta_{\mathrm{b}}\right)$, peak wave period $\left(T_{\mathrm{p}}\right)$, wave steepness $\left(H_{\mathrm{o}} / L_{\mathrm{o}}\right)$, wave 
energy $\left(E_{\mathrm{o}}\right)$, wave power $\left(P_{\mathrm{o}}\right)$, normalized wave power $\left(P n_{\mathrm{o}}\right)$, alongshore wave energy flux $\left(P l_{\mathrm{b}}\right)$, dimensionless fall velocity $(\Omega)$ and the dimensionless embayment scaling parameter $\left(\delta^{\prime}\right)$.

Deepwater conditions $\left(H_{0}, T_{\mathrm{p}}\right.$ and $\left.\theta_{\mathrm{o}}\right)$ are provided directly from the buoy measurements, while

261

262

263

264

265

266

267

268

269

270

271

272

273

274

275

276

277

278

279

280

281

282

283

284

285

286

287

$$
P_{\mathrm{o}}=E C_{\mathrm{g}}
$$
given by: $\left(P_{0}\right)$ :

breaking conditions $\left(H_{\mathrm{b}}\right.$ and $\left.\theta_{\mathrm{b}}\right)$ were computed using the formula presented by Larson et al. (2010), developed to derive wave properties at incipient breaking. The use of this simplified solution that employs the conservation of wave energy flux from an offshore location combined with Snell's law for wave refraction disregards wave diffraction around headlands. Although diffraction is an important factor in coastal embayments, this solution was chosen given the reduced headland extend for most study sites and the assumption that the use of such simplified solution is deemed suitable for spatialand time-averaged shoreline response studies, as it was found adequate to explore the relationships between wave forcing and the temporal eigenfunctions at the scale of interest (meters to kilometres / months to years) (Miller and Dean, 2007b). Depth limited breaking is imposed with the commonly used depth breaker ratio of 0.78 . Wave angles were converted in positive/negative angles for waves approaching northwards/southwards to beach normal for the west coast beaches, and waves approaching westwards/eastwards to beach normal for the south coast beaches.

Wave steepness, $H_{0} / L_{0}$, was calculated using linear wave theory with $L_{0}$, the deepwater wave length,

$L_{\mathrm{o}}=\left(g T_{\mathrm{p}}^{2}\right) /(2 \pi)$

where $g$ is the acceleration due to gravity. Offshore wave energy density $\left(E_{o}\right)$, or simply wave energy, was also computed considering linear wave theory:

$E_{\mathrm{o}}=(1 / 8) p g H_{\mathrm{o}}^{2}$

where $\rho$ is the density of water. Combining wave energy with the deepwater group velocity $\left(C_{g}\right)$ it is possible to compute the rate at which wave energy is transferred by moving waves, the wave power 
where $C_{g}$ is given by

290

291

$C_{\mathrm{g}}=(1 /(4 \pi)) g T_{\mathrm{p}}$

292

293

Recognizing the importance of tidal levels for coastal morphological evolution in Southern Portugal,

294

Morris et al. (2001) proposed the normalized wave power $\left(P n_{0}\right)$ in order to include the tidal range

295 according to:

296

297

$P n_{\mathrm{o}}=P_{\mathrm{o}}\left(\eta_{\mathrm{dtr}} / \eta_{\mathrm{str}}\right)$

298

299

where $\eta_{\mathrm{dtr}}$ is the maximum daily tidal range and $\eta_{\mathrm{str}}$ is the maximum spring tidal range. This parameter

300 conveniently reflects the enhanced wave erosion potential during spring tides, restricting it for lower

301 tidal ranges (Morris et al., 2001).

302 In order to obtain an indicator of the alongshore sediment transport, the alongshore component of the wave energy flux $\left(P l_{b}\right)$ was computed using:

304

305

$P l_{\mathrm{b}}=\left(E_{\mathrm{b}} C_{\mathrm{g}}\right) \sin \theta_{\mathrm{b}} \cos \theta_{\mathrm{b}}$

306

307

where $E_{\mathrm{b}}$ was obtained for breaking conditions according to Eq. (3) replacing $H_{\mathrm{o}}$ by $H_{\mathrm{b}}$, and $C_{\mathrm{g}}$ as given by the shallow water approximation to wave group velocity:

309

310

$C_{\mathrm{g}}=\sqrt{ }\left(g h_{\mathrm{b}}\right)$

where $h_{\mathrm{b}}$ is the water depth at breaking. According to the conversion of wave directions to wave angles positive/negative alongshore energy fluxes correspond to southward/northward transport for west coast beaches, and eastward/westward transport for the south coast beaches. Besides the purely hydrodynamic parameters presented above, the nearshore forcing can also be represented by parameterizations that incorporate sedimentary characteristics of the embayments. A natural parameter to consider, for its generalized application to beach studies, is the dimensionless fall velocity $(\Omega)$ (Gourlay, 1968; Dean, 1973): 
where $W_{\mathrm{s}}$ is the sediment fall velocity, computed according to Soulsby (1997) using the median grain diameter $\left(d_{50}\right)$ averaged for each embayment from beach face samples collected seasonally during the two year study period (Table 1). All the aforementioned parameters are well established in the literature and have proven skilfulness in characterizing morphological changes in the coastal environment. However, no parameter considers explicitly the impact of embayment dimensions and geometry in characterizing the nearshore environment. Short $(1996 ; 1999)$ based on unpublished work by Marteens and collaborators presented the dimensionless embayment scaling parameter $\left(\delta^{\prime}\right)$, which relates the embayment configuration to the incident breaking wave conditions according to:

where $S_{\mid}$is the embayment shoreline length and $C_{l}$ is the chord length (distance between headlands). This empirical approximation was derived from morphometric analysis of embayed beaches in order to describe parametrically the degree of headland impact on surf zone circulation considering a typical surfzone gradient of 0.01 (Short and Masselink, 1999).

\subsubsection{Correlation analysis}

Linear correlation analysis was used to test the hypothesis that EOF modes have a physical meaning, and are not simply by-products from the mathematical decomposition. Accordingly, if the temporal eigenfunctions of the EOF modes are related to the time series of at least one of the forcing parameters considered, their physical meaning should be elucidated by the characteristics of such forcing parameters (Miller and Dean, 2007b). Correlation between variables was considered statistically significant at the $95 \%$ confidence level when the Pearson's product moment correlation coefficient $(R)$ exceeded the critical level $\left(R_{\text {crit } 95 \%}\right)$ based on two-tailed normal distribution for $n-2$ degrees of freedom (DOF) (Table 1). More stringent correlation ( $\left.R_{\text {crit } 99 \%}\right)$, at the $99 \%$ confidence level,

348 is further used in order to distinguish the strongest correlations between the temporal eigenfunctions and the forcing parameters. 
As beach changes occur at different frequencies and response times may be site specific, a variable averaging interval for correlation with the temporal eigenfunctions was implemented. The forcing parameters were averaged over 1 to 30 days prior to each survey date, regardless of survey intervals, following Hansen and Barnard (2010) and Alvarez-Ellacuria et al. (2011). As there is no consensus about the optimal averaging interval for correlation of forcing parameters with temporal eigenfunctions (or the beach changes they are supposed to represent), the varying averaging window implemented provides a more flexible approach, enabling further exploration of the response times of each beach. Moreover, by extending from 1 to 30 days (D), the varying averaging window allows the incorporation of daily, weekly and monthly averaging intervals as in other studies (e.g. Miller and Dean, 2007b; Quartel et al., 2008). The averaging interval that produced the first peak in correlation above the critical level was assumed to be the optimal time scale of beach response, regardless of the fact that higher correlation may be obtained for larger averaging windows (refer to Figure 2 for an example of how peak correlation was obtained). The reasoning behind this option is that larger averaging intervals reflect responses to the seasonal variation in wave climate, as suggested by Miller and Dean (2007b), while the first peak in correlation more likely refers to the effects of boundaries in embayed beach response.

\section{Results}

The results of the EOF decomposition indicate that the first two eigenfunctions explain the majority of morphologic change, accounting for over $95 \%$ of the total variability in each embayment (Table 2). The first eigenfunction is undoubtedly the most important, contributing $67 \%$ to $94 \%$ of the total variance of each dataset, while the second eigenfunction only explains $4 \%$ to $29 \%$. The first two eigenfunctions, $e_{1}(s, t)$ and $e_{2}(s, t)$, will be analysed in detail bellow, based on the interpretation of spatial patterns and temporal amplitudes for each embayment (Figs. 4-9), and evaluation of their relation with forcing parameters (Table 3).

Over the two-year monitoring period, wave conditions for both sections of the Portuguese southwestern coastline were generally characterized by a concentration of energetic conditions in the periods between November and April, while during the remaining months waves are generally lower, although $H_{0}$ frequently exceeded $2 \mathrm{~m}$ in the west coast and $1 \mathrm{~m}$ in the south coast (Fig. 3). Peak wave directions were mostly constant year-round from the NW quadrant in the western section, while for the southern coast there was a striking alternation between SW and SE conditions (Fig. 3). Most 
382

383

384

385

386

387

388

389

390

391

392

393

394

395

396

397

398

399

400

401

402

403

404

405

406

407

408

409

410

411

412

413

significant events, highlighted in Figure 3, occurred due to rapid succession of high-energy conditions (storm-groups) and waves in excess of $6 \mathrm{~m}$ and $4 \mathrm{~m}$ for western and southern sections, respectively. Such events were concentrated in the first year of monitoring in the southern coast, while around the western section the most noteworthy event, composed by a group of five storms, occurred later, between late January and mid-February of 2009. This difference in the timing of the most extreme wave conditions had significant implications in the beach behaviour for the two sections of the coastline, as detailed in the following sections.

\subsection{Amoreira}

The primary mode of variability in Amoreira beach, representing $86 \%$ of the variance, consists of a nearly uniform alongshore pattern of beach response. The spatial eigenfunction $e_{1}(s)$ represents a coherent pattern of morphological change along the entire embayment, although with increased variability in the northern and central sections (Fig. 4). Despite this slight alongshore variation, it is evident that the beach responds as a whole, with changes characterized by alongshore uniform accretion and erosion. From January 2009, the temporal eigenfunction $c_{1}(t)$ exhibits a marked decrease (Fig.4), most likely related to extreme storm events along the southwestern Portuguese coast reported in Loureiro et al. (2011). Coefficients for $c_{1}(t)$ remained negative with reduced variation throughout the rest of the monitoring period. The temporal variability of the first eigenfunction is only significantly correlated with the normalized wave power $\left(P n_{\circ}\right)$ (Table 3). The negative correlation between $c_{1}(t)$ and $P n_{0}$, with a peak correlation value of $R=-0.51$ at $D=1$ day, highlights an immediate inverse association between the normalized wave power and beach volume.

The second mode of variability $e_{2}(s, t)$ accounts for $11 \%$ of the variance and exhibits opposing responses for the northern and southern beach ends. This alongshore non-uniform pattern of $e_{2}(s)$ presents a nodal point located near the centre of the embayment (Fig. 4), and higher variability for the southern section of the beach, adjacent to the stream inlet. Phase shifts between opposing ends of embayed beaches are associated with rotation phenomena (Short, 1999; Klein et al., 2002), and at Amoreira positive/negative phases correspond to clockwise/anticlockwise rotation about the nodal point in the central section of the beach. Mode two temporal eigenfunction $c_{2}(t)$ is strongly correlated with several forcing parameters (Table 3). Highly significant correlations include the forcing parameters $H_{\mathrm{b}}, T_{\mathrm{p}}, E_{\mathrm{o}}, P_{\mathrm{o}}$ and $\delta$, while $P l_{\mathrm{b}}$ and $\Omega$ are also significantly correlated but at $95 \%$ confidence level. The averaging windows for peak correlations with the aforementioned parameters are similar, ranging from 6 to 8 days preceding surveys. Correlation is positive for all these parameters 
(except $\delta^{\prime}$ ), implying that increases in $H_{\mathrm{b}}$ and $T_{\mathrm{p}}$, with concomitant increases in $E_{\mathrm{o}}, P_{\mathrm{o}}$ and $\Omega$ (and

415

416

417

418

419

420

421

422

423

424

425

426

427

428

429

430

431

432

433

434

435 decrease in $\left.\delta^{\prime}\right)$ are translated into a clockwise rotation of the embayment with sediment transferences from the northern section towards the southern section. Anti-clockwise rotation occurs for low waves, and is possibly mediated by the increasing influence of stream discharge and tidal prism under low waves, allowing the development of a secondary stream channel flowing northwards along the foreshore (Freire et al., 2011). Although breaker angle alone lacks any significant correlation with $c_{2}(t)$, correlation with $P l_{b}$ provides additional support to the rotation interpretation, as a positive linear relationship implies clockwise (anticlockwise) rotation due to positive-southwards (negativenorthwards) alongshore wave energy flux.

\subsection{Mt. Clérigo}

The spatial eigenfunction $e_{1}(s)$ at Mt. Clérigo beach indicates a uniform pattern of morphological change, with a slightly higher variability in the central section (Fig. 5). Similarly to Amoreira beach, the combined eigenfunctions for $e_{1}(s, t)$ (Fig. 5), demonstrate an embayment-wide morphological response, with a seasonal signal. Accretion occurs during summer conditions and erosion in winter. Again, the negative peak after January 2009 marks the occurrence of extreme storm events. This temporal variability of $c_{1}(t)$ is significantly correlated with $P n_{\circ}(R=-0.65$ at $D=1)$. The strong negative correlation peaking at the shorter averaging window suggests a prompt morphological response to changing wave conditions when normalised by the tide.

The second mode eigenfunction for Mt. Clérigo is alongshore non-uniform (Fig. 5). This alongshore non-uniform pattern is consistent with beach rotation behaviour, characterized by the out of phase response between both ends of the embayment (Fig. 5). Significant correlations were found between $c_{2}(t)$ and the parameters $H_{\mathrm{b}}, \Omega$ and $\delta$, with peak values obtained for $D=1$ day. While the spatial eigenfunction $e_{2}(s)$ is consistent with a rotation scenario, the absence of correlation between $c_{2}(t)$ and the two forcing parameters that include directional information, $\theta_{\mathrm{b}}$ and $P l_{\mathrm{b}}$, indicates that rotation is not likely related with directional forcing. Highly significant correlation with $\delta$ ' does, however, suggest that surf zone circulation, with development of rip current systems driven by variations in the obliquity of wave approach as proposed by Loureiro et al. (2012), may be the cause of this apparent rotation between opposite extremes of the beach.

\subsection{Arrifana}


Arrifana is the longest yet most indented embayment among the westerly exposed beaches. Mode one eigenfunction $e_{1}(\mathrm{~s}, t)$ for this beach follows the general pattern identified for the other embayments. The spatial variability $e_{1}(s)$ indicates that the beach responds uniformly with both ends experiencing similar, but more extreme, changes than the central section (Fig. 6). The timing of these changes displays identical seasonal signal to the one described for Mt. Clérigo and Amoreira. Several forcing parameters are significantly correlated with $c_{1}(t),\left(H_{\mathrm{b}}, T_{\mathrm{p}}, E_{\mathrm{o}}, P_{\mathrm{o}}, P n_{\mathrm{o}}, P \mathrm{l}_{\mathrm{b}}\right.$ and $\left.\Omega\right)$. Given the particularly strong negative correlation with $P n_{0}$, already noted for the other embayments, but with a wider peak averaging window $(D=12)$, it is likely that the higher confinement of Arrifana promotes a delayed morphological response comparing to the more exposed embayments, possibly due to enhanced attenuation of the local wave climate.

Mode two spatial eigenfunction $e_{2}(s)$ presents an alongshore non-uniform behaviour, characterized by higher variability in the central section (Fig. 6). Two nodal points occur near the extremities of the beach, lessening the magnitude of changes close to site boundaries for this EOF. None of the forcing parameters is significantly correlated with $c_{2}(t)$, which restricts the physical interpretation of this mode. Development of circulation cells at the extremities of the beach with onshore re-attachment of sub- to inter-tidal crescentic bars in the central section has been observed in this embayment. These possibly embody a mechanism for beach recovery following rip-induced erosion reported during storms at Arrifana (Loureiro et al., 2012). However, such hypothesis cannot be confirmed, as the forcing parameter $\delta$ ', which characterizes embayment surfzone circulation, provided no statistically significant support.

\subsection{Salema}

Salema is the embayment where $e_{1}(s, t)$ ranks the lower relative importance, representing roughly $67 \%$ of the variance (Table 2). Absence of nodal points for $e_{1}(s)$ indicates that morphological changes are synchronous at the entire embayment, with the central and western sectors concentrating the bulk of the variability (Fig. 7). Correlation of $c_{1}(t)$ is statistically significant with several parameters, as indicated in Table 3, particularly those derived from an energetics-based approach to hydrodynamic forcing. The stronger correlations are again obtained with $P n_{0}$, displaying a negative signal and peak correlations at $D=10$ days.

Given the lower relative importance of $e_{1}(s, t)$, mode two eigenfunction $e_{2}(s, t)$ has a more significant contribution for explaining the variability in Salema dataset $(29 \%)$. This eigenfunction is consistent with the beach rotation scenario, with a nodal point close to the central section of the beach (Fig. 7). The 
combined spatial and temporal eigenfunctions also support the hypothesis of beach rotation, and outof-phase behaviour is evident in Fig. 7. Correlation analysis of $c_{2}(t)$ with forcing parameters reinforces this interpretation, with direction-dependent parameters $\left(\theta_{b}\right.$ and $\left.P l_{b}\right)$ presenting significant correlations, peaking at 6 to 7 days preceding surveys (Table 3). Given the strong association between direction and wave period for the southern Portuguese coast (WSW swell with longer $T_{\mathrm{p}}$ or locally generated SE sea with shorter $\left.T_{\mathrm{p}}\right)$, both $T_{\mathrm{p}}$ and $H_{\mathrm{o}} / L_{\mathrm{o}}$ present very significant correlations with $c_{2}(t)$, further emphasising the wave-forced beach rotation scenario.

\subsection{Boca do Rio}

The primary mode of variability $e_{1}(s, t)$ in Boca do Rio presents an alongshore uniform pattern of beach change, with slight differences between beach sectors, generally describing a coherent response throughout the entire embayment (Fig. 8). The first mode eigenfunction is marked by a decrease in the temporal amplitude $c_{1}(t)$ in the first six months of study, followed by an invariant trend, occasionally disturbed by short lived peaks of beach accretion (Fig. 8). This unusual temporal variability is not correlated to any forcing parameter (Table 3) hampering the physical interpretation of mode one in Boca do Rio.

Mode two spatial eigenfunction $e_{2}(s)$ for Boca do Rio follows the pattern of beach rotation previously described. The strong correlation of $c_{2}(t)$ with $\theta_{\mathrm{b}}$ and $P l_{\mathrm{b}}$, for identical averaging windows (Table 3 ), confirms the hypothesis of a short-term beach rotation scenario at Boca do Rio.

\subsection{Cabanas Velhas}

Cabanas Velhas primary mode of variability $e_{1}(s, t)$ is also characterized by a coherent alongshore pattern with higher variability for $e_{1}(s)$ in the eastern sector (Fig. 9). The chronology of the changes described for Cabanas Velhas $c_{1}(t)$ is analogous to Boca do Rio $c_{1}(t)$, but with a sharper decrease in the first few months of study. Strong negative correlations were obtained between $c_{1}(t)$ and $P n_{0}$, peaking at $D=4$ days, reflecting the short-term inverse response to wave conditions along the entire embayment, enhanced by the effects of tidal range variation.

The second mode spatial variability $e_{2}(s)$ is alongshore non-uniform, with two nodal points closer to the extremes and an area of higher variability in the central section of the embayment (Fig. 9). Variability of $e_{2}(s, t)$ is consistent with the occurrence of erosion and accretion pulses in the central section of the beach, possibly with a partial contribution to and from the eastern section. Positive correlation values ( $R=0.36$ to 0.37 ) and long averaging windows ( $D=17$ to 18 days) between $c_{2}(t)$ 
509

510

511

512

513

514

515

516

517

518

519

520

521

522

523

524

525

526

527

528

529

530

531

532

533

534

535

536

537

538

539

540

and wave forcing parameters $H_{\mathrm{b}}, E_{\mathrm{o}}, P_{\mathrm{o}}, \Omega$, suggests that accretionary pulses might occur under moderate to high waves. Although necessarily below the storm threshold value $\left(H_{0} \geq 3 \mathrm{~m}\right)$, higher than average wave forcing is likely to promote the transfer of sediment from the subtidal terrace to the intertidal beach in the bedrock fronted central section of Cabanas Velhas, similar to the effect of large swells in reef-fronted beaches (Miller and Fletcher, 2003).

\section{Discussion}

\subsection{Forcing parameters and response times}

Selection of forcing parameters for exploring beach and nearshore morphological behaviour is not obvious or straightforward. Other parameters, reflecting similar nearshore forcing, where considered, for example, by Miller and Dean (2007b) and Fairley et al. (2009) in comparable EOF analysis of morphological change. However, observed significant correlations at the $99 \%$ confidence level with at least one of the selected parameters for most eigenfunctions substantiates the validity of our choices. In the results presented here, only two eigenfunctions, $c_{2}(t)$ in Arrifana and $c_{1}(t)$ in Boca do Rio, were uncorrelated with the forcing parameters selected. This highlights the case for caution in the interpretation of EOF decompositions, as physical significance of EOF modes can be misleading (Dommenget and Latif, 2002). However, when statistically significant correlation can be identified with meaningful forcing parameters, as shown by the majority of the eigenfunctions analysed, physical interpretation of EOF modes should be considered with confidence (Miller and Dean, 2007b).

From all parameters considered, a marked consistency in strong negative correlation was identified between the first mode eigenfuntion and normalized wave power $\left(P n_{\circ}\right)$ in all embayments, with the exception of Boca do Rio. Such correlation agrees with the findings of Fairley et al. (2009), where the first mode eigenfunction of shoreline variability behind detached breakwaters was also negatively correlated with a proxy combining wave and tidal forcing. $P n_{\circ}$ always provides the stronger correlation with $c_{1}(t)$, highlighting that the incorporation of tidal range variability for normalizing wave power enhances the explanatory ability of this parameter to describe morphological behaviour, as suggested by Morris et al. (2001). This has implications for energetics-based modelling of coastal changes, as this reasoning might be applied to template models of coastal change in meso to macrotidal beaches (e.g. Yates et al., 2009).

Recent modelling and data-analysis work using EOFs on a Mediterranean embayed beach by Alvarez-Ellacuria et al. (2011) indicates a decoupling of response times in morphological behaviour. In 
541

542

543

544

545

546

547

548

549

550

551

552

553

554

555

556

557

558

559

560

561

562

563

564

565

566

567

568

569

570

their results, longshore response attributed to the second mode eigenfunction lags cross-shore response associated with the first mode eigenfunction by three days. This decoupling pattern is noticeable in several of the study sites presented here, although not holding consistently for all embayments. Most cases, however, appear to reflect a lag in response times, as evidenced for Amoreira with the first temporal eigenfunction peak correlation at $D=1$ day, while the second mode eigenfunction peaks at $D=7$ to 8 days (Table 3 ). Less frequently, both modes peak at the same averaging interval (e.g. Mt. Clérigo with $D=1)$. Such site-specific response times are likely the result of diverse degrees of exposure and compartmentalization of the various embayments. The general lag for mode two confirms the suggestions of Alvarez-Ellacuria et al. (2011) that the cross-shore and longshore components elucidated do not respond simultaneously, and also of Miller and Dean (2007b) that each mode has a particular response time. Assumptions that on decadal timescales cross-shore processes have a shorter-term response time that longshore processes (Lazarus and Murray, 2007), seem to be applicable also on monthly to seasonal timescales even for highly localized responses. Compartmentalization appears, however, to significantly influence response times, with longer response times in more constrained embayments (e.g. Arrifana).

Given the inclusion of dedicated post-storm surveys in the analysis, a potential bias for faster response times was further investigated considering exclusively the bi-monthly surveys. Results, not shown here, indicate varied behaviour between embayments. Mt. Clérigo and Arrifana presented identical response times considering all surveys and bimonthly surveys only, while Amoreira and Boca to Rio presented slower response times, which increased between 1 and 11 days. In contrast, at Salema response times were 4 to 10 days faster considering only the bimonthly surveys, while at Cabanas Velhas no statistical significant correlations with forcing parameters were found considering exclusively bi-monthly surveys. The reduced number of bimonthly surveys (13) compared to the entire dataset (20 to 33 ; Table 1$)$ implied higher thresholds for statistical significant correlations $\left(R_{\text {crit } 95 \%}>\right.$ \pm 0.55 and $R_{\text {crit } 99 \%}> \pm 0.68$ ), which justify the results observed in Cabanas Velhas, as correlations were already low considering the entire dataset (Table 3). Despite variations in response times, for which no clear storm-related bias was evidenced, most notable changes pertain to the $22 \%$ reduction in the forcing parameters for which statistical significant correlations were identified. Again, reduction in survey number and, consequently, more stringent thresholds for statistical significant correlation justifies such variation. 


\subsection{Mechanisms for alongshore variability}

Although early spatial and temporal decompositions of morphological variability using EOF analysis in embayed beaches provide indications that morphological change is associated with nearshore circulation cells (Clarke and Elliot, 1982, 1988; Clarke et al., 1984), most recent studies using this technique have identified beach rotation as the core mechanism of alongshore non-uniformity in embayed beaches (Short et al., 2000; Munõz-Pérez et al., 2001; Short and Trembanis, 2004; Harley et al., 2008; Ruiz de Alegría-Arzaburu et al., 2010). The results shown here, with four beaches presenting second mode eigenfunctions typical of rotation mechanisms, further emphasize the role of beach rotation as a prevailing mode of alongshore variability in embayed beaches. Our results also confirm the ability of EOF analysis to extract the rotation component from diverse datasets. Wave direction-forced beach rotation is, however, not consistently supported for all cases. While at Salema and Boca do Rio statistically significant correlation of $c_{2}(t)$ with both $\theta_{\mathrm{b}}$ and $P l_{\mathrm{b}}$ translates a clear directionally-forced rotation behaviour, expectable under the bi-directional wave climate of southern Portugal, the out of phase pattern observed also in Amoreira and Mt. Clérigo is unlikely to be attributable to a similar mechanism.

The appearance of beach rotation (when the extremes of an embayment are out of phase and a nodal point or transition zone exists (Klein et al., 2002)), can in fact be promoted by physical processes other than directionally forced alongshore sediment transport as recently demonstrated by Harley et al., (2011). Given the strength and signal of the correlation between various forcing and $c_{2}(t)$ at Amoreira (Table 3), clockwise rotation occurs in this embayment under energetic waves, while anti-clockwise rotation develops during low wave conditions. Such behaviour is most likely the result of complex nonlinear interactions involving wave conditions, tidal prisms and fluvial discharge of the shallow coastal stream within Amoreira embayment (Oliveira et al., 2010; Freire et al., 2011). In Mt. Clérigo, the surf zone circulation is suggested as the driver of the out-of-phase response within the embayment for the second mode eigenfunction. Three-dimensional cellular circulation, with extensive rip current systems, has been shown to determine morphological change in Mt. Clérigo (Loureiro et al., 2012). The formation, evolution and clogging of rip and feeder channels, along with the displacement of nearshore bars drives alongshore non-uniform variability producing an inverse response between the extremes of the embayment, similar to findings of Ojeda and Guillén (2008). Strong correlation of $c_{2}(t)$ with $\delta$ ' at Mt. Clérigo (Table 3) further validates this hypothesis. 
Presumed independence of two- and three-dimensional components in coastal morphological change

605

606

607

608

609

610

611

612

613

614

615

616

617

618

619

620

621

622

623

624

625

626

627

628

629

630

631

632

633

634

635

renders EOF decomposition a particularly useful tool for coastal research (Ruessink et al., 2000).

Accordingly, nearly all studies of alongshore variability using EOFs in embayed beaches succeeded in isolating the cross-shore component present in the first eigenfunction, describing the bulk of the variability, from the alongshore components in lower-rank eigenfunctions (e.g. Clarke and Eliot, 1982; Short et al., 2000; Harley et al., 2008; Alvarez-Ellacuria et al., 2011). General acceptance of this decoupled morphological response elucidated by the EOF analysis provides a further opportunity to examine the boundary effects in the morphological response of embayed beaches. Vertical boundary effects should be revealed by the variability of the first mode eigenfunction, assumed to represent twodimensional cross-shore response, while the second mode eigenfunction, embodying threedimensional alongshore response, ought to portray the effects of lateral boundaries For all embayments presented here the first mode eigenfunction corresponds to a roughly uniform spatial trend without zero crossings (or nodal points), although not necessarily linear. In the present context, variability in the spatial amplitudes of this eigenfunction is presumed to represent variable two-dimensional geological constraints. Lower $e_{1}(s)$ amplitudes are indicative of the limitation to free profile fluctuation by underlying hard rock (Clarke and Eliot, 1982; Vousdoukas et al., 2007), implying an effective vertical boundary control on beach profile evolution. The specific mechanisms that determine this constrained dynamics are not yet adequately understood (Gallop et al., 2011b), as they are a result of complex morphodynamic interference of rocky hard-bottoms with beach morphologic change (Larson and Kraus, 2000; Vousdoukas et al., 2007). However, it is generally considered that profile behaviour is dependent on the depth and shape of the underlying geological control (Jackson et al., 2005; Jackson and Cooper, 2009). As such, significant differences exist between the moderateenergy sediment-deprived south coast beaches and the high-energy sediment-richer west coast beaches. Considering both south and west coast embayments in the conceptual framework of Jackson and Cooper (2009), our results place west coast dissipative embayments within the vertical unconstrained beach type, while Salema more likely conforms to the semi-constrained and Boca do Rio and Cabanas Velhas are undoubtedly in the highly-constrained beach type.

South coast embayments, Salema, Boca do Rio and Cabanas Velhas, clearly show evidence of vertical boundary effects, and sectors where underlying geological control is shallower present reduced $e_{1}(s)$ amplitudes, increasing towards sections with deeper sediment veneers. This gradation can be observed in all three embayments, with the eastern sector in Salema and the western sector in Boca do Rio and Cabanas Velhas displaying minimums in the first mode spatial eigenfuntion (Fig. 7 to 
Fig. 9). Variable depths of the vertical boundary also imply diverse temporal response for hydrodynamic forced profile modification. Within the south coast beaches, Salema displays temporal variability of $c_{1}(t)$ broadly consistent with a seasonal forced response, while Boca do Rio and Cabanas Velhas present roughly invariant trends for $c_{1}(t)$ following severe erosion in the first months of monitoring. Muñoz-Perez et al. (2010) suggested that geologically controlled beach profiles are prone to erosive trends and less able to recover during accretionary periods, and this appears to be the case in the south coast beaches presented here. Thin veneers of sediment covering the underlying rocky substrate in Boca do Rio and Cabanas Velhas were easily eroded in the first months of monitoring. Recovery was limited and both embayments remained depleted by the end of the monitoring period. The limited sediment contained within Salema embayment is, nonetheless, sufficient to enable the development of a sub-aerial beach profile that varies seasonally with significant recovery volumes, as demonstrated by the variability of $c_{1}(t)$. Such varied behaviour of south coast embayments confirms the suggestions of Muñoz-Perez et al., (2010), further emphasizing an enhancement in recovery ability as sediment depth increases. Vertical boundary effects in west coast beaches are less readily apparent from the first mode eigenfunction. The underlying geological control is significantly deeper and was never exposed for most profiles, yet there are variations in the spatial amplitude of the first mode eigenfunctions, particularly noticeable in Arrifana embayment. Mechanisms other than direct influence of underlying rocky substrate must be considered for the west coast beaches. The highly three-dimensional nearshore behaviour of these high-energy beaches, where large scale rip systems develop during storms and persist for several months (Loureiro et al., 2012), appears to be responsible for the variable spatial amplitudes of $e_{1}(s)$, as the topographically-controlled location of such rip systems is consistent with the areas of increased variability for $e_{1}(s)$.

659 Effects of lateral boundaries have received far more attention in studies of morphological variation in embayed beaches, and an established base of literature exists now demonstrating the utility of EOF analysis in extracting the rotation component from morphological change datasets (e.g. Short et al., 2000; Munõz-Pérez et al., 2001; Short and Trembanis, 2004; Miller and Dean, 2007a; Harley et al., 2008; Ruiz de Alegría-Arzaburu et al., 2010). A characteristic rotation pattern for the second mode spatial eigenfunction, with a nodal point separating sectors of inverse morphological response, facilitates interpretation. In most cases, such lateral boundary effects are manifested in embayed 
associated with the spatial patterns of beach rotation, as in Salema and Boca do Rio, lateral boundaries unequivocally exert their effects by disrupting longshore sediment transport. However, lateral boundary effects can also be manifested through modification of nearshore circulation (Short, 1999). Interpretation of nearshore circulation mechanisms, particularly topographically-controlled rip currents, is not as straightforward as directionally forced beach rotation due to irregular EOF spatial amplitude patterns (Clarke and Eliot, 1982). Nevertheless, correlation with forcing parameters sensitive to beach type and morphodynamic behaviour, notably $\Omega$ and $\delta$, does provide indications of the importance of laterally constrained nearshore circulation mechanisms in the three-dimensional behaviour of Cabanas Velhas, Mt. Clérigo and Amoreira embayments. In coastal embayments it is generally assumed that boundary effects will influence only the sections close to the headlands, leaving a central section relatively unaffected by the site boundaries (Short, 1999; Miller and Dean, 2007a). While this is likely to be the case in wide embayments, the six study sites presented here are clearly small embayments and boundary effects are manifested along the entire beach.

Our original hypothesis that vertical and lateral geological boundaries constrain the morphological behaviour of embayed beaches is abundantly supported by the results. Moreover, although it is not possible to state that the relative importance of two- and three dimensional changes directly relates to the variances explained respectively by the first and second mode eigenfunctions, a clear relation exists between these two variables, as postulated by Ruessink et al. (2000). Such distinction provides support to our secondary hypothesis that boundary effects can be decoupled from datasets of embayed beach morphological change.

Finally, a framework for boundary effects in geologically constrained embayed beaches is proposed (Fig. 10), which considers a basic control on boundary effects by the sedimentary budget. Sediment abundant embayed beaches, with large accommodation spaces, are generally unaffected by vertical boundary effects. They are, however, prone to exhibit lateral boundary effects through constraining of nearshore 3D circulation and/or longshore sediment transport. The relative importance of these processes varies inversely in response to changes in embayment indentation and obliquity of wave approach. Within sediment-deprived embayments the controls on boundary effects are determined mainly by substrate depth and wave obliquity. Increases in both parameters enhance lateral boundary effects, frequently promoting beach rotation, while reductions impose constrains on the cross-shore sediment transport leading to reduced profile fluctuation. 


\section{Conclusions}

702

703

704

705

706

707

708

709

710

711

712

713

714

715

716

717

718

719

720

721

722

723

724

725

726

727

728

729

730

731

This study shows that natural geological boundaries constrain the morphological behaviour of embayed beaches, determining diverse spatial and temporal variability patterns within the six embayments analysed. Localized responses produced by lateral and vertical boundary interference with nearshore dynamics, including beach rotation, topographic-controlled rip circulation and subdued profile fluctuation, are suggested as the primary drivers of alongshore non-uniform morphological variability. Examination of second mode eigenfunction is consistent with recent work suggesting that directionally forced beach rotation is the most frequent mode of alongshore variability in embayed beaches. Rotation patterns can, however, also emerge due to cellular circulation mechanisms or even as a result of complex interactions involving wave conditions, tidal prisms and fluvial discharge of shallow coastal streams.

EOF decomposition confirms suggestions of a spatial decoupling in cross- and longshore responses. Variable peak correlation of temporal amplitudes and forcing parameters also indicates a decoupling in cross- and longshore response times, which appear to increase for more constrained embayments. Highly significant peak correlations of the normalized wave power with the first mode of morphological variability further suggests that, for exposed mesotidal coastal environments, a parameter combining wave and tide variability is likely to increase process-response relations between hydrodynamic forcing and morphological change.

Lateral and vertical geological boundaries exert their effects fundamentally by restraining longshore sediment transport, inducing cellular surf zone circulation and by impacting cross-shore sediment transport. While sediment abundance is suggested as the fundamental element determining boundary effects, embayment indentation, wave obliquity and substrate depth are considered decisive to determine the morphological impact of vertical and lateral geological boundaries.

\section{Acknowledgements}

This work is a contribution to Project BAYBEACH - Evolution and Management of Embayed Beaches in Contrasting Environments, funded by FCT under contract PTDC/CTE-GEX/66893/2006. Carlos Loureiro was supported by FCT, grant reference SFRH/BD/27878/2006. Hydrodynamic data was provided by Instituto Hidrográfico. Modelled WANA wave data were supplied by Puertos del Estado. We gratefully acknowledge the help of everyone involved in the fieldwork data collection, frequently 
under severe weather conditions. We are especially grateful to Mara Nunes (CIMA - UALG) for valuable assistance during surveying and Lluís Gómez-Pujol (SOCIB - IMEDEA) for thoughtful insights and documentation regarding EOF analysis.

\section{References}

Almeida, L.P., Ferreira, Ó., Pacheco, A., 2011. Thresholds for morphological changes on an exposed sandy beach as a function of wave height. Earth Surface Processes and Landforms 36, 523-532.

Archetti, R., Romagnoli, C., 2011. Analysis of the effects of different storm events on shoreline dynamics of an artificially embayed beach. Earth Surface Processes and Landforms 36, 14491463.

Aubrey, D.G., 1979. Seasonal patterns of onshore/offshore sediment movement. Journal of Geophysical Research 84 (C10), 6347-6354.

Clarke, D.J., Eliot, I.G., 1982. Description of littoral, alongshore sediment movement from empirical eigen-function analysis. Journal of the Geological Society of Australia 29, 327-341.

Clarke, D.J., Eliot, I.G., 1988. Low-frequency changes of sediment volume on the beachface at Warilla beach, New South Wales, 1975-1985. Marine Geology 79, 189-211.

Clarke, D.J., Eliot, I.G., Frew, J.R., 1984. Variation in subaerial beach sediment volume on a small sandy beach over a monthly lunar tidal cycle. Marine Geology 58, 319-344.

Costa, M., Esteves, R., 2010. Clima de agitação marítima na costa oeste de Portugal Continental. Proceedings of XI Jornadas Técnicas de Engenharia Naval - O Sector Marítimo Português. Edições Salamadra, Lisboa. 413-426.

Costa, M., Silva, R., Vitorino, J., 2001. Contribuição para o estudo do clima de agitação marítima na costa Portuguesa. Proceedings of 2as Jornadas de Engenharia Costeira e Portuária. AIPCN, Aveiro, 20 p. (CD-ROM).

Dean, R.G., 1973. Heuristic models of sand transport in the surf zone. Proceedings of the Conference on Engineering Dynamics in the Surfzone. Institute of Engineers, Sydney, Australia, 208-214.

Dean, R.G., Dalrymple, R.A., 2002. Coastal Processes with Engineering Applications. Cambridge University Press, Cambridge.

Dommenget, D., Latif, M., 2002. A cautionary note on the interpretation of EOFs. Journal of Climate $15,216-225$.

Fairley, I., Davidson, M., Kingston, K., Dolphin, T., Philips, R., 2009. Empirical orthogonal function analysis of shoreline changes behind two different designs of detached breakwaters. Coastal Engineering 56, 1097-1108.

Finkelstein, K., 1982. Morphological variations and sediment transport in crenulate-bay beaches, Kodiak Island, Alaska. Marine Geology 47, 261-281. 
Freire, P., Taborda, R., Bertin, X., Guerreiro, M., Fortunato, A.B., Silva, A.M., Andrade, C., Oliveira, A., Antunes, C., Freitas, M.C., Nahon, A., Rodrigues, M., Bruneau, N., 2011. Medium-term morphodynamic evolution of a small coastal inlet. Journal of Coastal Research SI 64, 666-670.

Gallop, S.L., Bosserelle, C., Pattiaratchi, C.B., Eliot, I., 2011a. Hydrodynamic and morphological response of a perched beach during sea breeze activity. Journal of Coastal Research SI 64, 7879.

Gallop, S.L., Bosserelle, C., Pattiaratchi, C.B., Eliot, I., 2011b. Rock topography causes spatial variation in the wave, current and beach response to sea breeze activity. Marine Geology 290, 2940.

Gómez-Pujol, L., Orfila, A., Álvarez-Ellacuría, A., Tintoré, J., 2011. Controls on sediment dynamics and medium-term morphological change in a barred microtidal beach (Cala Millor, Mallorca, Western Mediterranean). Geomorphology 132, 87-98.

Gourlay, M.R., 1968. Beach and Dune Erosion Tests I. Report M935/M936, Delft Hydraulics Laboratory, $117 \mathrm{p}$.

Hansen, J.E., Barnard, P.L. 2010. Sub-weekly to interannual variability of a high-energy shoreline. Coastal Engineering 57, 959-972.

Harley, M.D., Turner, I.L., Short, A.D, Ranasinghe, R., 2008. Rotation and oscillation of an embayed beach. Proceedings of the $31^{\text {st }}$ International Conference on Coastal Engineering. World Scientific Publishing, Singapore. 865-875.

Harley, M.D., Turner, I.L., Short, A.D, Ranasinghe, R., 2011. A reevaluation of coastal embayment rotation: the dominance of cross-shore versus alongshore transport processes, CollaroyNarrabeen Beach, southeast Australia. Journal of Geophysical Research 116, F040033.

Haxel, J.H., Holman, R.A., 2004. The sediment response of a dissipative beach to variations in wave climate. Marine Geology 206 73-99.

Hsu, J.R.C., Benedet, L., Klein, A.H.F., Raabe, A.L.A., Tsai, C.P., Hsu, T.W., 2008. Appreciation of static bay beach concept for coastal management and protection. Journal of Coastal Research 24, 198-215.

Jackson, D.W.T., Cooper, J.A.G., 2009. Geological control on beach form: accommodation space and contemporary dynamics. Journal of Coastal Research SI 56, 69-72.

Jackson, D.W.T., Cooper, J.A.G., del Rio, L., 2005. Geological control of beach morphodynamic state. Marine Geology 216, 297-314.

Klein, A.H.F, Benedet, L., Schumacher, D.H., 2002. Short-term beach rotation processes in distinct headland bay beach systems. Journal of Coastal Research 18, 442-458.

Klein, A.H.F, Ferreira, Ó., Dias, J.M.A., Tessler, M.G., Silveira, L.F., Benedet, L., Menezes, J.T., Abreu, J.G.N., 2010. Morphodynamics of structurally controlled headland-bay beaches in southeastern Brazil: a review. Coastal Engineering 57, 98-111. 
804

805

806

807

808

809

810

811

812

813

814

815

816

817

818

819

820

821

822

823

824

825

826

827

828

829

830

831

832

833

834

835

836

837

838

839

840

Kroon, A., Larson, M., Möller, I., Yokoki, H., Rozynsky, G., Cox, J., Larroude, P., 2008. Statistical analysis of coastal morphological data sets over seasonal to decadal time scales. Coastal Engineering 55, 581-600.

Lahoz, M.G., Albiach, J.C.C., 2005. Wave forecasting at the Spanish coasts. Journal of Atmospheric \& Ocean Science 10, 389-405.

Larson, M., Capobianco, M., Jansen, H., Rózynski, G., Southgate, H.N., Stive, M., Wijnberg, K.M., Hulscher, S., 2003. Analysis and modelling of field data on coastal morphological evolution over yearly and decadal time scales. Part 1: background and linear techniques. Journal of Coastal Research 19, 760-775.

Larson, M., Hanson, H., Kraus, N.C., Newe, J., 1999. Short- and long-term responses of beach fills determined by EOF analysis. Journal of Waterway, Port, Coastal and Ocean Engineering 125, 285-293.

Larson, M., Hoan, L.X., Hanson, H., 2010. Direct formula to compute wave height and angle at incipient breaking. Journal of Waterway, Port, Coastal and Ocean Engineering 136, 119-122.

Larson, M., Kraus, N.C., 2000. Representation of non-erodible (hard) bottoms in beach profile change modelling. Journal of Coastal Research 16, 1-14.

Lazarus, E.D., Murray, A.B., 2007. Process signatures in regional patterns of shoreline change on annual to decadal time-scales. Geophysical Research Letters 34, L19402.

Loureiro, C., Ferreira, Ó., Cooper, J.A.G., 2011. Morphologic change and morphodynamics at highenergy embayed beaches in southwestern Portugal. Proceedings of Coastal Sediments '11. World Scientific Publishing, Singapore. Vol. 2, 1375-1389.

Loureiro, C., Ferreira, Ó., Cooper, J.A.G., 2012. Extreme erosion on high-energy embayed beaches: influence of megarips and storm groups. Geomorphology (in press). DOI:10.1016/j.geomorph.2011.10.013.

Martins, C.C., Mahiques, M.M., Dias, J.M.A., 2010. Daily morphological changes determined by highenergy events on an embayed beach: a qualitative model. Earth Surface Processes and Landforms 35, 487-495.

Masselink, G., Pattiaratchi, C.B., 2001. Seasonal changes in beach morphology along the sheltered coastline of Perth, Western Australia. Marine Geology 172, 243-263.

Miller, J.K., Dean, R.G., 2007a. Shoreline variability via empirical orthogonal function analysis: Part I temporal and spatial characteristics. Coastal Engineering 54, 111-131.

Miller, J.K., Dean, R.G., 2007b. Shoreline variability via empirical orthogonal function analysis: Part II relationship to nearshore conditions. Coastal Engineering 54, 133-150.

Miller, T.L., Fletcher, C.H., 2003. Waikiki: historical analysis of an engineered shoreline. Journal of Coastal Research 19, 1026-1043.

Morris, B.D., Davidson, M., Huntley, D., 2001. Measurements of the response of a coastal inlet using video monitoring techniques. Marine Geology 175, 251-272. 
Muñoz-Perez, J.J., Medina, R., 2010. Comparison of long-, medium- and short-term variations of beach profiles with and without submerged geological control. Coastal Engineering 57, 241-251.

Muñoz-Pérez, J.J., Medina, R., Tejedor, B., 2001. Evolution of longshore beach contour lines determined by the E.O.F. method. Scientia Marina 65, 393-402.

Ojeda, E., Guillén, J., 2008. Shoreline dynamics and beach rotation of artificial embayed beaches. Marine Geology 253, 51-62.

Oliveira, A., Fortunato, A.B., Guerreiro, M., Bertin, X., Bruneau, N., Rodrigues, M., Taborda, R., Andrade, C., Silva, A.M., Antunes, C., Freire, P., Pedro, S.L., Dodet, G., Loureiro, C., Mendes, A., 2010. Effect of inlet morphology and wave action on transport and sediment dynamics in a coastal stream. Proceedings of the Eleventh International Conference on Estuarine and Coastal Modeling. ASCE Conference Proceedings 388, 601-620.

Phillips, J.D., 1985. Headland-bay beaches revisited: an example from Sandy Hook, New Jersey. Marine Geology 65, 21-31.

Quartel, S., Kroon, A., Ruessink, B.G., 2008. Seasonal accretion and erosion patterns of a microtidal sandy beach. Marine Geology 250, 19-33.

Ranasinghe, R., McLoughlin, R., Short, A.D., Symonds, G., 2004. The Southern Oscillation Index, wave climate and beach rotation. Marine Geology 204, 273-287.

Ruessink, B.G., van Enckevort, I.M.J., Kingston, K.S., Davidson, M.A., 2000. Analysis of observed two- and three-dimensional nearshore bar behaviour. Marine Geology 169, 161-183.

Ruiz de Alegría-Arzaburu, A., Masselink, G., 2010. Storm response and beach rotation on a gravel beach, Slapton Sands, UK. Marine Geology 278, 77-99.

Ruiz de Alegría-Arzaburu, A.R., Pedrozo-Acuña, A., Horrillo-Caraballo, J.M., Masselink, G., Reeve, D.E., 2010. Determination of wave-shoreline dynamics on a macrotidal gravel beach using Canonical Correlation Analysis. Coastal Engineering 57, 290-303.

Sanderson, P.G., Eliot, I., 1999. Compartmentalisation of beachface sediments along the southwestern coast of Australia. Marine Geology 162, 145-164.

Scott, T., Masselink, G., Russel, P., 2011. Morphodynamic characteristics and classification of beaches in England and Wales. Marine Geology 286, 1-20.

Short, A.D., 1996. The role of wave height, period, slope, tide range and embaymentisation in beach classifications: a review. Revista Chilena de Historia Natural 69, 589-604.

Short, A.D., 1999. Handbook of Beach and Shoreface Morphodynamics. John Wiley \& Sons, Chichester.

Short, A.D., 2010. Role of geological inheritance in Australian beach morphodynamics. Coastal Engineering 57, 92-97.

Short, A.D., Trembanis, A.C., Turner, I.L., 2000. Beach oscillations, rotation and the southern oscillation, Narrabeen Beach, Australia. Proceedings of the $27^{\text {th }}$ International Conference on Coastal Engineering. ASCE, Sydney. 2439-2452. 
Short, A.D., Trembanis, A.C., 2004. Decadal scale patterns in beach oscillation and rotation, Narrabeen Beach, Australia - time series, PCA and wavelet analysis. Journal of Coastal Research 20, 523-532.

Silvester, R., 1985. Natural headland control of beaches. Continental Shelf Research, 4, 581-596.

Silvester, R., Hsu, J.R.C., 1997. Coastal Stabilization. World Scientific, Singapore. 578 p.

Soulsby, R.L., 1997. Dynamics of Marine Sands: a manual for practical applications. Thomas Telford, London.

Thomas, T., Phillips, M.R., Williams, A.T., 2010. Mesoscale evolution of a headland bay: beach rotation processes. Geomorphology 123, 129-141.

Thomas, T., Phillips, M.R., Williams, A.T., Jenkins, R.E., 2011. Short-term beach rotation, wave climate and the North Atlantic Oscillation (NAO). Progress in Physical Geography 35, 333-352.

van Enckevort, I.M.J., Ruessink, B.G., 2003. Video observations of nearshore bar behaviour. Part 2: alongshore non-uniform variability. Continental Shelf Research 23, 513-532.

Vincent, L., Dolan, R., Hayden, Resio, D., 1976. Systematic variations in barrier-island topography. Journal of Geology 84, 583-594.

Vousdoukas, M.I., Velegrakis, A.F., Plomaritis, T.A., 2007. Beachrock occurrence, characteristics, formation mechanisms and impacts. Earth-Science Reviews 85, 23-46.

Vousdoukas, M.I., Velegrakis, A.F., Karambas, T.V., 2009. Morphology and sedimentology of a microtidal beach with beachrocks: Vatera, Lesbos, NE Mediterranean. Continental Shelf Research 29, 1937-1947.

Wijnberg, K.M., Terwindt, J.H.J., 1995. Extracting decadal morphological behaviour from highresolution, long-term bathymetric surveys along the Holland coast using eigenfunctions analysis. Marine Geology 126, 301-330.

Winant, C.D., Inman, D.L., Nordstrom, C.E., 1975. Description of seasonal beach changes using empirical eigenfunctions. Journal of Geophysical Research 80, 1979-1986.

Yates, M.L., Guza, R.T., O’Reilly, W.C., 2009. Equilibrium shoreline response: observations and modelling. Journal of Geophysical Research 114, C09014.

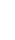

.

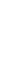


913

\section{List of Tables}

914

915

916

917

918

919

920

921

922

923

924

925

926

927

928

929

930

931

932

933

934

935

936

937

938

939

940

941

942

943

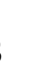

Table 1 - Summary of the relevant characteristics of the monitoring sites and correlation criteria.

Table 2 - Percentage of the variance explained by the first two eigenfunctions at each site.

Table 3 - Pearson's product moment correlation coefficient's between the temporal eigenfunctions $\left(c_{n}(t)\right)$ for the peak $D$ days average of the hydrodynamic forcing parameters preceding each survey (only correlations at the $95 \%$ or higher confidence levels are presented). 


\section{List of Figures}

945

946

947

948

949

950

951

952

953

954

955

956

957

958

959

960

961

962

963

964

965

966

967

968

969

970

971

972

973

Figure 1 - Geographic location and aerial view of the study sites (indicated by black circles in the map). Location of beach profiles, directional wave buoys, modelled wave points and tide gauges indicated by black lines, asterisks, stars and doted circles, respectively. Wave roses for Sines and Faro were computed from wave buoy data (asterisks in location image), from 2007 to 2009.

Figure 2 - Linear correlation $(R)$ between forcing parameters $\Omega$ (black line) and $P n_{\circ}$ (grey dotted line) and the first temporal eigenfunction $\left(c_{1}(t)\right)$ for Arrifana beach. Results are presented for the averaging windows of 1 to 30 days prior to each survey. Averaging days $(D)$ for the first peak in correlation above the $R_{\text {crit } 95 \%}$ level are indicated for each forcing parameter.

Figure 3 - Time series of offshore significant wave height $\left(H_{0}\right)$ and peak wave direction $\left(\theta_{0}\right)$ over the two-year monitoring period (September 2007 to September 2009). Top panels refer to Sines wave buoy, representative of conditions along the western coastline, and bottom panels refer to Faro buoy, representative of conditions along the southern coastline. Grey shading highlights most significant high-energy events on each coastline section.

Figure 4 - Normalized spatial $\left(e_{n}(s)\right)$ and temporal $\left(c_{n}(t)\right)$ eigenfunctions for Amoreira beach dataset (upper panels). Reconstruction of the first two EOF modes, based on the combined analysis of the spatial and temporal eigenfunctions (lower panels). North, Centre and South are relative to the profiles location at the beach.

Figure 5 - Normalized spatial $\left(e_{n}(s)\right)$ and temporal $\left(c_{n}(t)\right)$ eigenfunctions for Mt. Clérigo beach dataset (upper panels). Reconstruction of the first two EOF modes, based on the combined analysis of the spatial and temporal eigenfunctions (lower panels). North, Centre and South are relative to the profiles location at the beach.

Figure 6 - Normalized spatial $\left(e_{n}(s)\right)$ and temporal $\left(c_{n}(t)\right)$ eigenfunctions for Arrifana beach dataset (upper panels). Reconstruction of the first two EOF modes, based on the combined analysis of the 
974

975

976

977

978

979

980

981

982

983

984

985

986

987

988

989

990

991

992

993

994

spatial and temporal eigenfunctions (lower panels). North, Centre and South are relative to the profiles location at the beach.

Figure 7 - Normalized spatial $\left(e_{n}(s)\right)$ and temporal $\left(c_{n}(t)\right)$ eigenfunctions for Salema beach dataset (upper panels). Reconstruction of the first two EOF modes, based on the combined analysis of the spatial and temporal eigenfunctions (lower panels). West, Centre and East are relative to the profiles location at the beach.

Figure 8 - Normalized spatial $\left(e_{n}(s)\right)$ and temporal $\left(c_{n}(t)\right)$ eigenfunctions for Boca do Rio beach dataset (upper panels). Reconstruction of the first two EOF modes, based on the combined analysis of the spatial and temporal eigenfunctions (lower panels). West, Centre and East are relative to the profiles location at the beach.

Figure 9 - Normalized spatial $\left(e_{n}(s)\right)$ and temporal $\left(c_{n}(t)\right)$ eigenfunctions for Cabanas Velhas beach dataset (upper panels). Reconstruction of the first two EOF modes, based on the combined analysis of the spatial and temporal eigenfunctions (lower panels). West, Centre and East are relative to the profiles location at the beach.

Figure 10 - Conceptual framework describing boundary effects in embayed beaches 


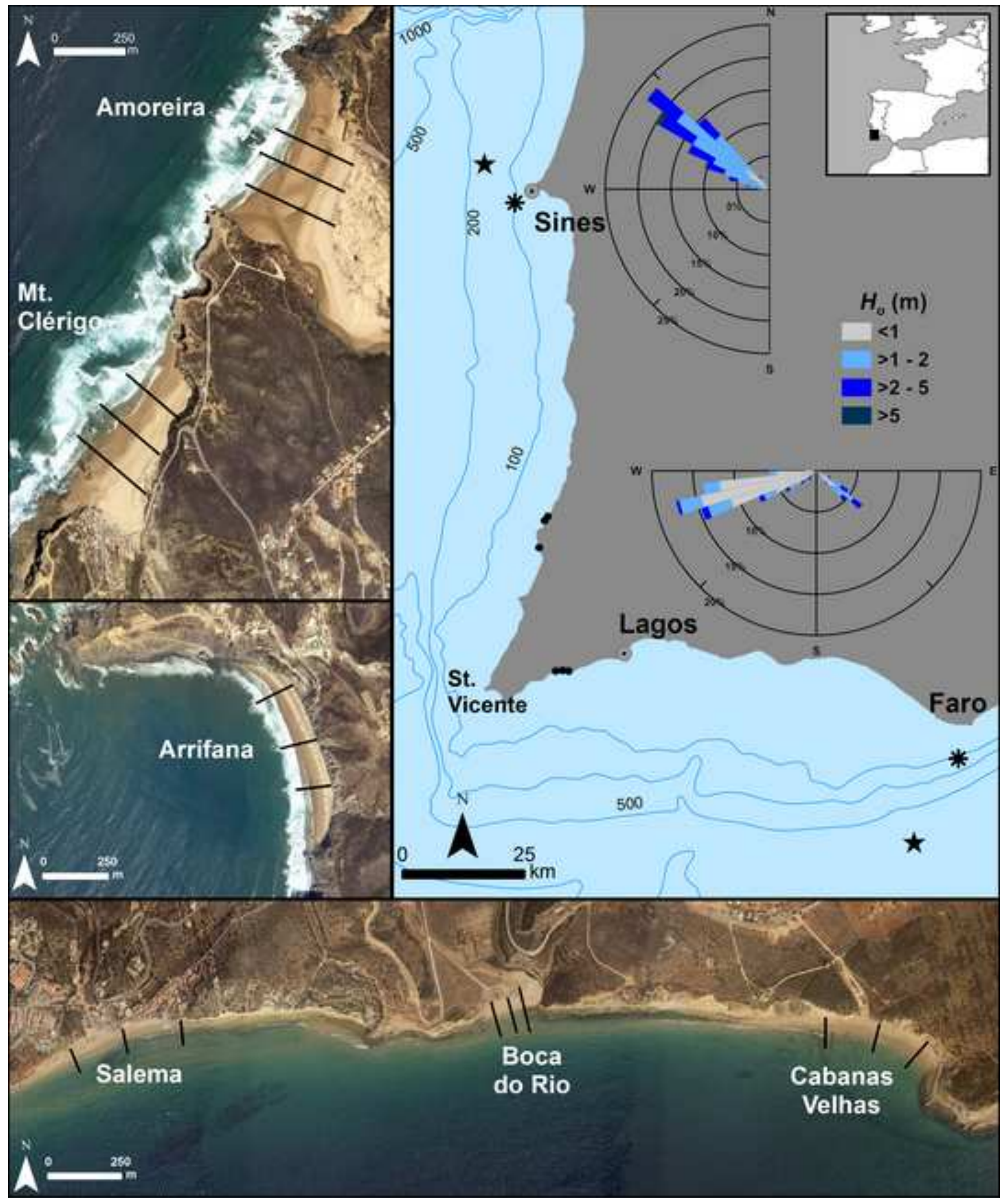




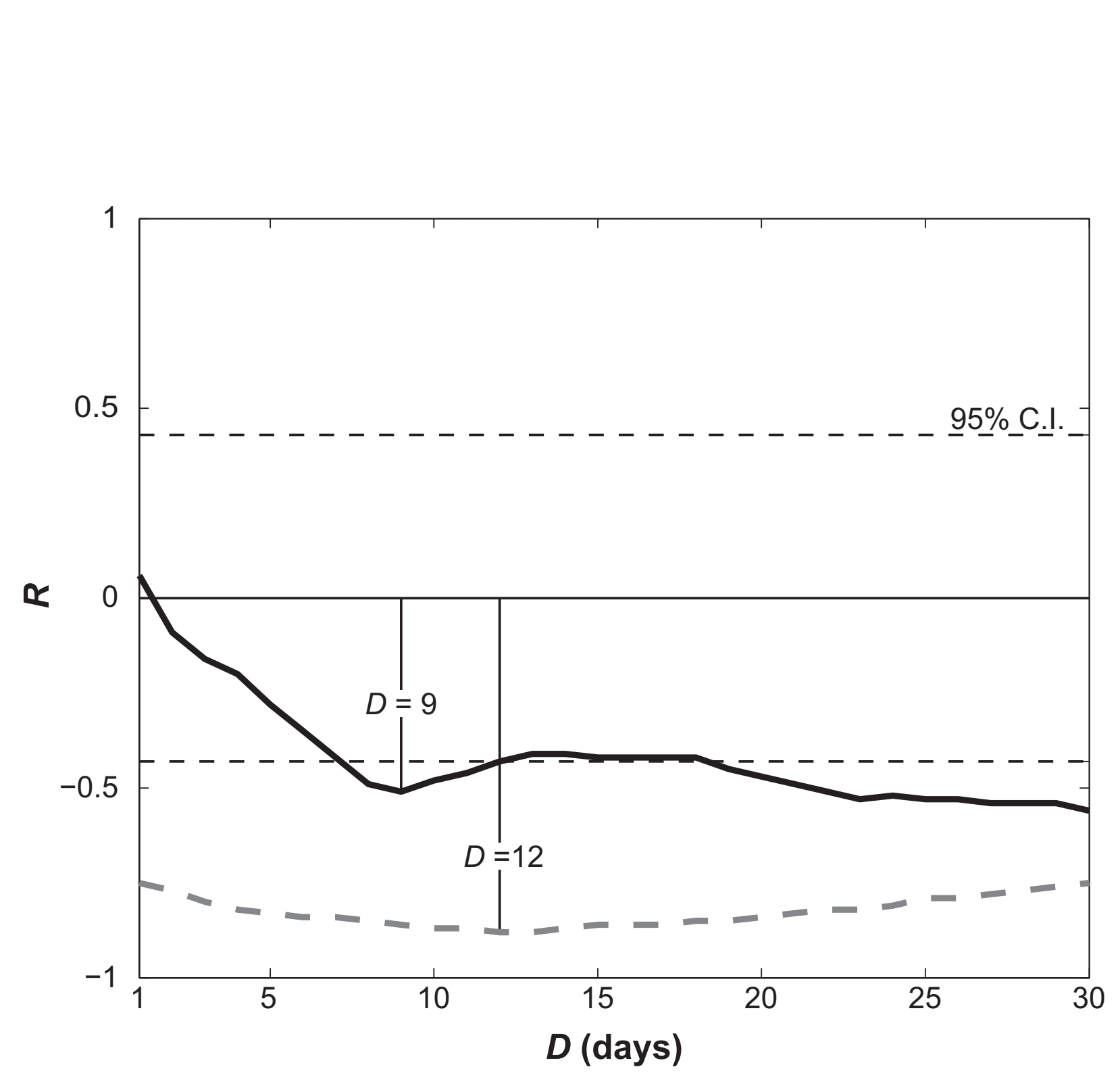

Figure 2

2

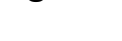

.
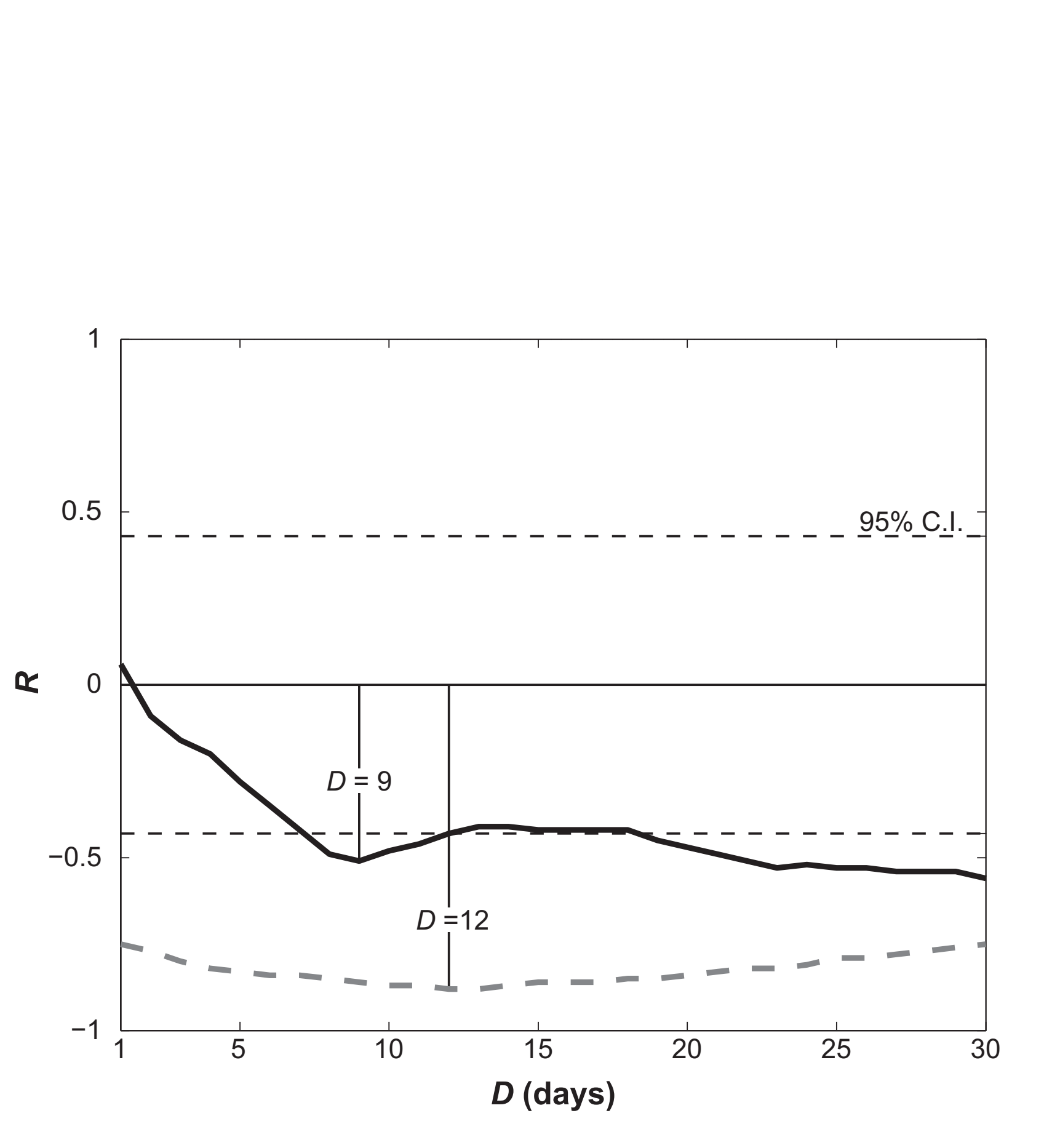

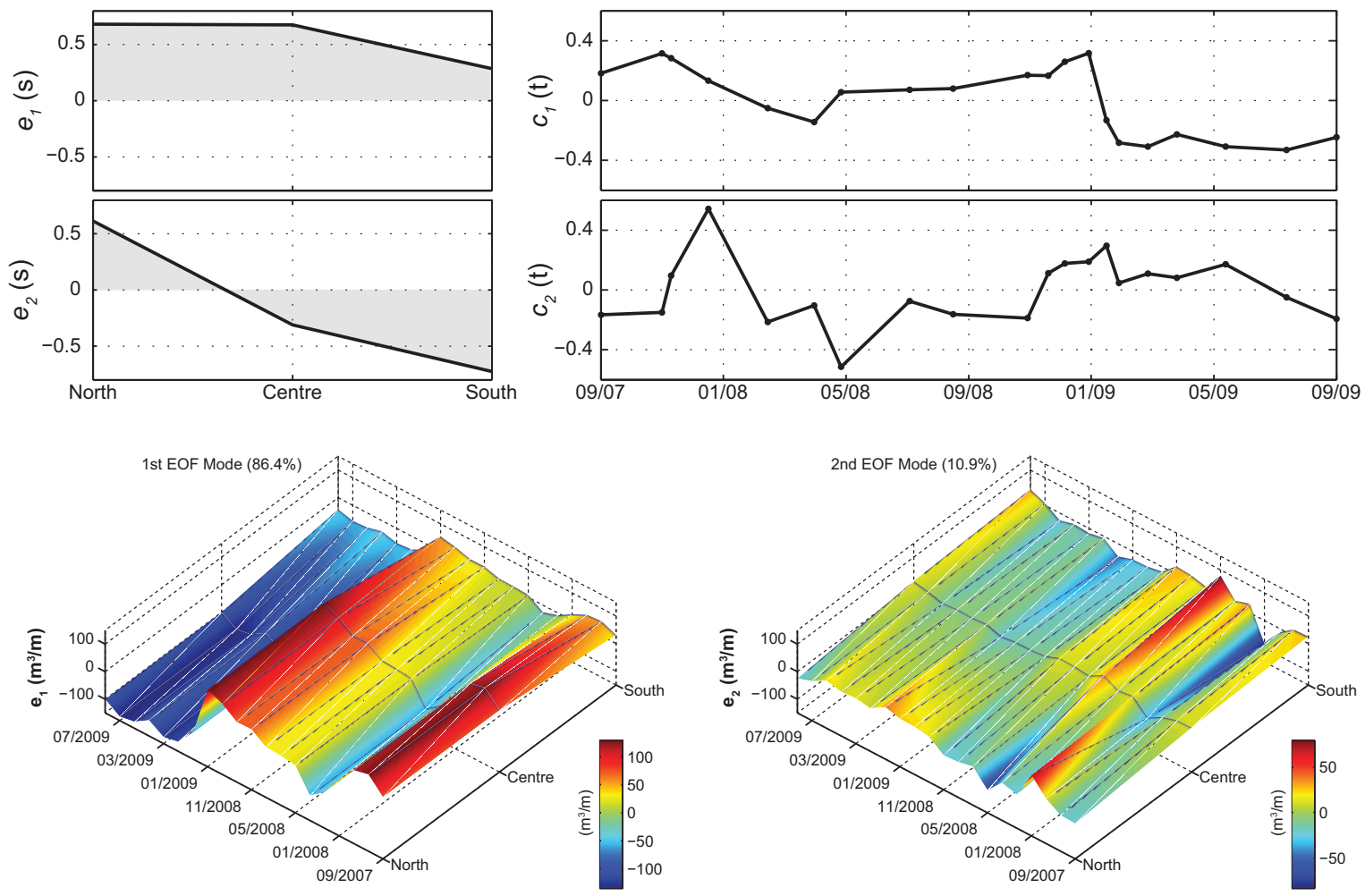

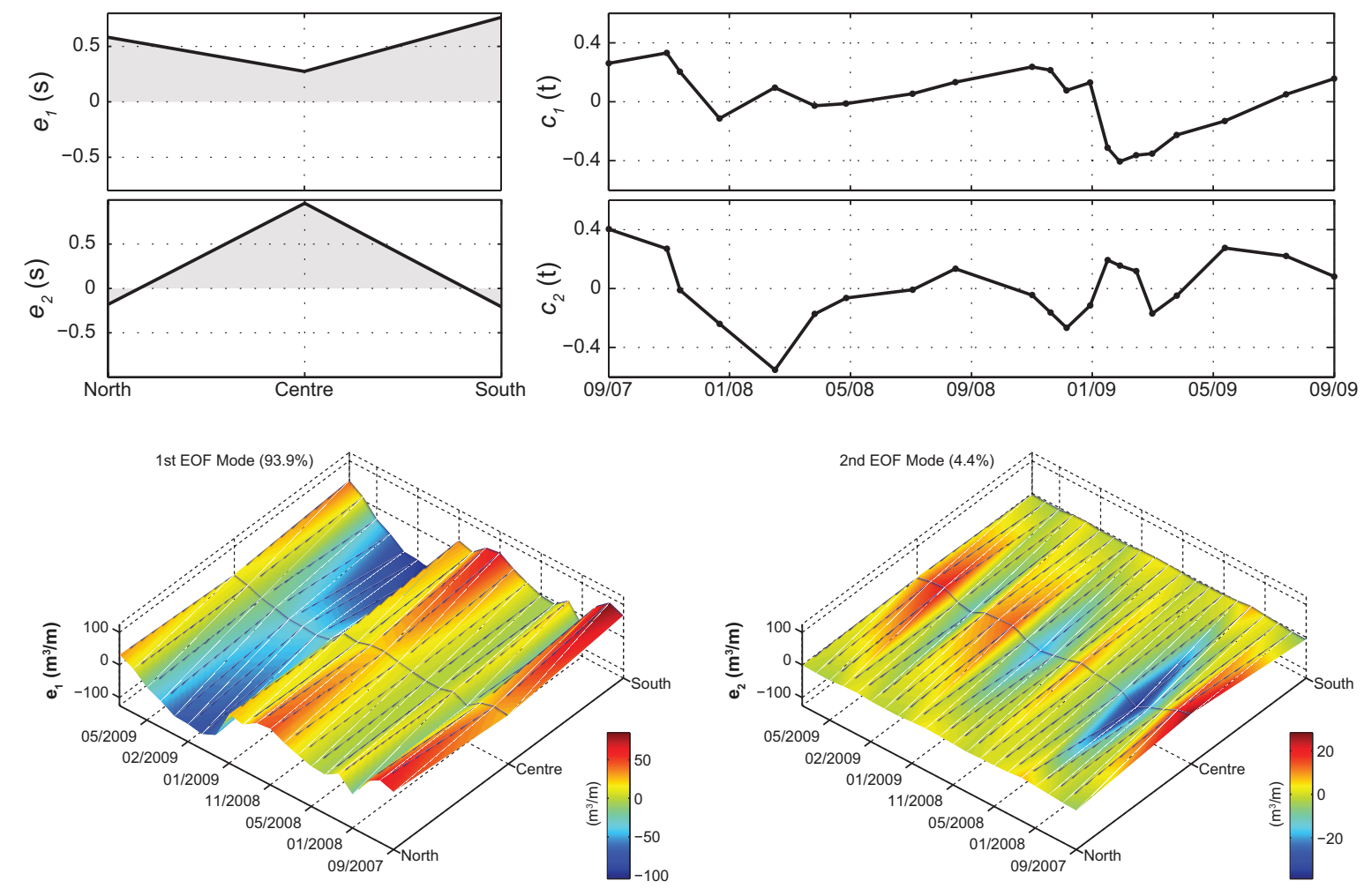

$$
\text { . }
$$



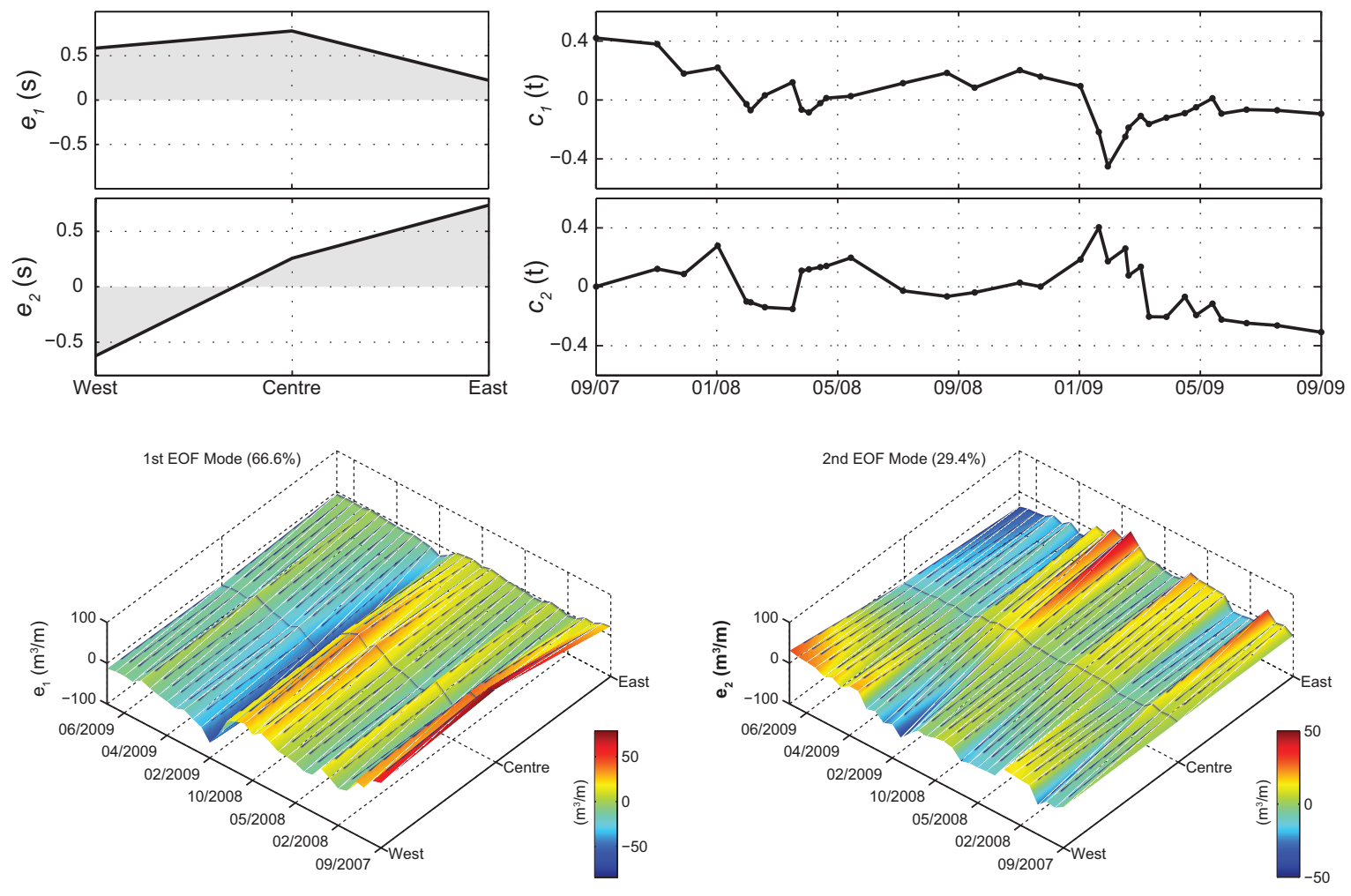

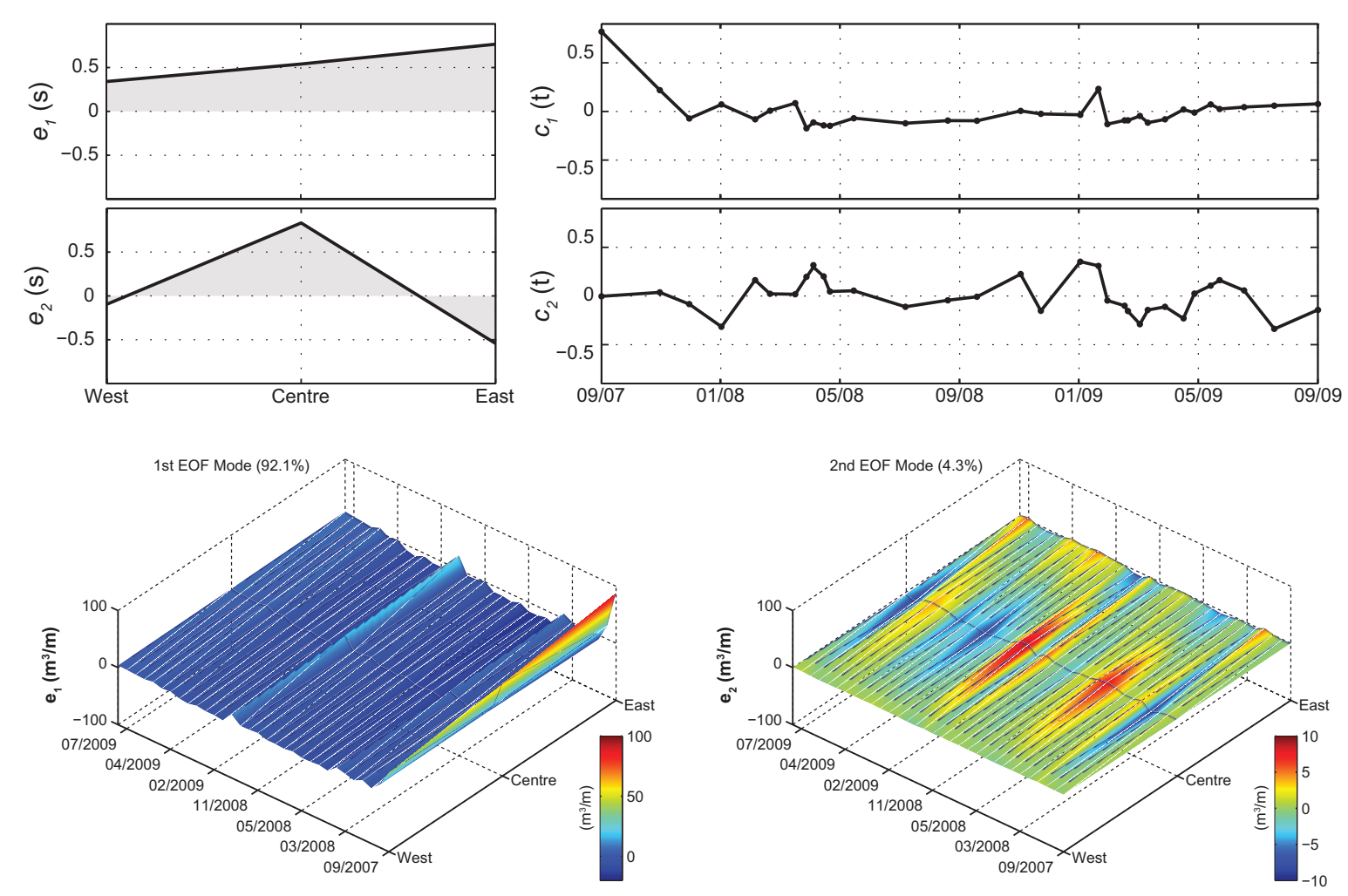


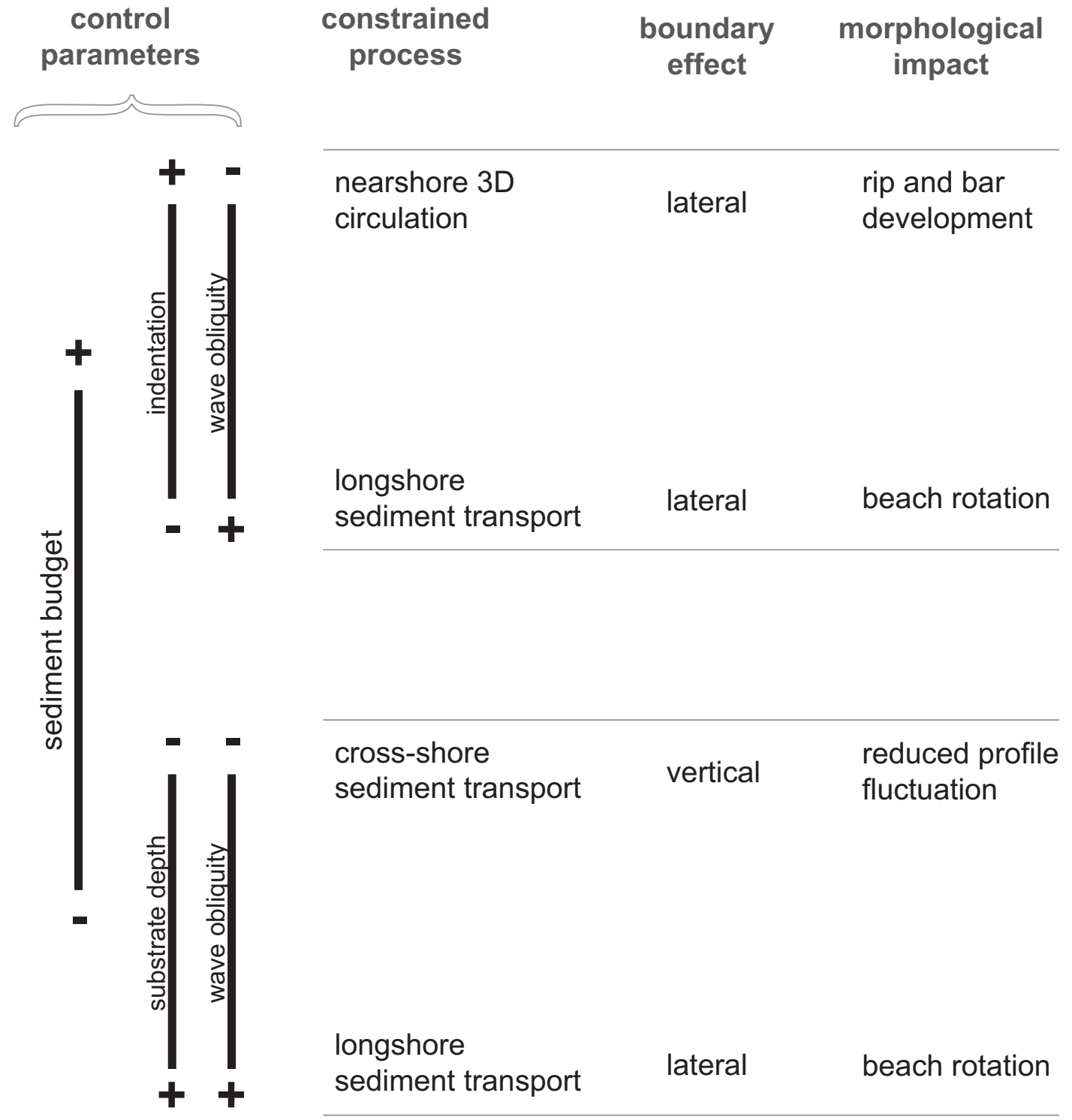

(2)

constrained

nearshore 3D

longshore

sediment transport

cross-shore

sediment transport

longshore

lateral

beach rotation
morphological impact

rip and bar

development reduced profile

uctuation

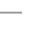




\section{Table 1}

Summary of the relevant characteristics of the monitoring sites and correlation criteria

\begin{tabular}{|c|c|c|c|c|c|c|c|c|c|c|}
\hline \multirow[b]{2}{*}{ Dataset } & \multicolumn{3}{|c|}{ Embayment dimensions } & \multicolumn{2}{|c|}{ Sediment data } & \multicolumn{2}{|c|}{ Beach profiles } & \multicolumn{3}{|c|}{ Correlation criteria } \\
\hline & $\begin{array}{r}\boldsymbol{S}_{\mathbf{I}} \\
(m)\end{array}$ & $\begin{array}{l}\boldsymbol{C}_{\mathbf{l}} \\
(m)\end{array}$ & $\begin{array}{l}\boldsymbol{B}_{\mathbf{1}} \\
(m)\end{array}$ & $\begin{array}{l}\boldsymbol{d}_{50} \\
(\mathrm{~mm})\end{array}$ & $\begin{array}{l}\boldsymbol{W}_{\mathbf{s}} \\
(\mathrm{m} / \mathrm{s})\end{array}$ & $\begin{array}{l}\text { Spacing } \\
\text { (m) }\end{array}$ & Surveys & DOF & $\boldsymbol{R}_{\text {crit } 95 \%}$ & $\boldsymbol{R}_{\text {crit } 99 \%}$ \\
\hline Amoreira & 815 & 575 & 600 & 0.298 & 0.037 & 115 & 20 & 18 & 0.44 & 0.56 \\
\hline Mt. Clérigo & 955 & 785 & 580 & 0.309 & 0.039 & 140 & 20 & 18 & 0.44 & 0.56 \\
\hline Arrifana & 2055 & 1340 & 830 & 0.268 & 0.032 & 205 & 21 & 19 & 0.43 & 0.55 \\
\hline Salema & 1300 & 1235 & 560 & 0.304 & 0.038 & 195 & 33 & 31 & 0.34 & 0.44 \\
\hline Boca do Rio & 255 & 195 & 180 & 0.406 & 0.054 & 55 & 32 & 30 & 0.35 & 0.45 \\
\hline Cabanas Velhas & 835 & 715 & 650 & 0.281 & 0.034 & 170 & 32 & 30 & 0.35 & 0.45 \\
\hline
\end{tabular}

Abbreviations indicated in the text. Additionally, $B_{1}$ stands for beach length. 
Table 2

Percentage of the variance explained by the first two eigenfunctions at each site

\begin{tabular}{llll}
\hline \multirow{2}{*}{ Dataset } & \multicolumn{3}{l}{ Percent of variance explained } \\
\cline { 2 - 4 } & $\boldsymbol{e}_{\boldsymbol{1}}(\mathbf{s}, \boldsymbol{t})$ & $\boldsymbol{e}_{\mathbf{2}}(\mathbf{s}, \boldsymbol{t})$ & Remaining \\
\hline Amoreira & $86,43 \%$ & $10,93 \%$ & $2,64 \%$ \\
Mt. Clérigo & $91,41 \%$ & $6,94 \%$ & $1,65 \%$ \\
Arrifana & $93,96 \%$ & $4,44 \%$ & $1,60 \%$ \\
Salema & $66,66 \%$ & $29,40 \%$ & $3,94 \%$ \\
Boca do Rio & $87,45 \%$ & $8,48 \%$ & $4,07 \%$ \\
Cabanas & $92,10 \%$ & $4,33 \%$ & $3,57 \%$ \\
\hline
\end{tabular}




\section{Table 3}

Pearson's product moment correlation coefficient's between the temporal eigenfunctions $\left(c_{n}(t)\right)$ for the peak D days averages of the hydrodynamic forcing parameters preceding each survey (only correlations at the $95 \%$ or higher confidence levels are presented).

\begin{tabular}{|c|c|c|c|c|c|c|c|c|c|c|}
\hline \multirow{2}{*}{ Dataset } & \multicolumn{10}{|c|}{ Correlation with forcing parameters } \\
\hline & $H_{\mathrm{b}}$ & $\boldsymbol{\theta}_{\mathrm{b}}$ & $T_{\mathrm{p}}$ & $H_{0} / L_{0}$ & $E_{\mathrm{o}}$ & $P_{\mathrm{o}}$ & $P n_{0}$ & $P I_{\mathrm{b}}$ & $\mathbf{\Omega}$ & $\delta^{\prime}$ \\
\hline \multicolumn{11}{|c|}{ Amoreira } \\
\hline$c_{1}(t)$ & -- & -- & -- & -- & -- & -- & $-0.51(1)$ & -- & -- & -- \\
\hline$c_{2}(t)$ & $0.65(8)$ & -- & $0.68(8)$ & -- & $0.62(7)$ & $0.65(7)$ & -- & $0.48(6)$ & $0.52(8)$ & $-0.58(8)$ \\
\hline \multicolumn{11}{|c|}{ Mt. Clérigo } \\
\hline$c_{1}(t)$ & - & - & - & - & - & -- & $-0.65(1)$ & - & -- & - \\
\hline$c_{2}(t)$ & $-0.49(1)$ & -- & -- & -- & -- & -- & -- & - & $-0.51(1)$ & $0.59(1)$ \\
\hline \multicolumn{11}{|l|}{ Arrifana } \\
\hline$c_{1}(t)$ & $-0.52(9)$ & -- & $-0.49(24)$ & -- & $-0.54(9)$ & $-0.54(9)$ & $-0.88(12)$ & $0.49(5)$ & $-0.51(9)$ & - \\
\hline$c_{2}(t)$ & -- & -- & -- & -- & -- & -- & -- & - & -- & -- \\
\hline \multicolumn{11}{|l|}{ Salema } \\
\hline$c_{1}(t)$ & -- & -- & $-0.38(15)$ & -- & $-0.40(20)$ & $-0.38(11)$ & $-0.53(10)$ & -- & -- & -- \\
\hline$c_{2}(t)$ & - & $0.41(6)$ & $0.63(15)$ & $-0.41(18)$ & -- & $0.36(24)$ & $0.37(25)$ & $0.35(7)$ & -- & $-0.43(15)$ \\
\hline \multicolumn{11}{|c|}{ Boca do Rio } \\
\hline$c_{1}(t)$ & - & - & - & -- & -- & -- & -- & -- & -- & - \\
\hline$c_{2}(t)$ & -- & $0.55(4)$ & $0.44(4)$ & $-0.38(2)$ & -- & -- & - & $0.55(3)$ & $-0.35(2)$ & - \\
\hline \multicolumn{11}{|c|}{ Cabanas } \\
\hline$c_{1}(t)$ & $-0.35(30)$ & -- & -- & $-0.36(14)$ & $-0.37(29)$ & $-0.36(30)$ & $-0.49(4)$ & - & $-0.40(19)$ & $0.37(17)$ \\
\hline$c_{2}(t)$ & $0.37(17)$ & -- & -- & -- & $0.36(18)$ & $0.37(17)$ & -- & -- & $0.37(17)$ & -- \\
\hline
\end{tabular}

Values between parentheses indicate the averaged $D$ days preceding each survey when 